\title{
Determination of Water Vapor from the Change in Elec- trical Resistance of a Hydroscopic Film
}

\author{
Elmer R. Weaver, Ernest E. Hughes, and Albert W. Diniak*
}

\begin{abstract}
The electrical conductivity of a thin film of such a material as phosphoric acid changes over a wide range with changes in the concentration of water in the atmosphere with which it is in contact. By adjusting the pressures of a sample of gas of known composition and one of unknown composition, they can be made to have the same concentration of water (more accurately the same fugacity) shown by the production of equal resistances of the detecting film. Modifications of the apparatus, procedures, and calculations described in an earlier publication are presented and numerous applications of the method are discussed. The method has the merits of simplicity, speed, and great sensitivity. Only small samples are needed, and few substances interfere.
\end{abstract}

\section{Introduction}

\subsection{Purpose of Paper}

This paper is a revision and extension of an earlier one $[1]^{1}$ now out of print. Several improvements have been made in methods of building and using the apparatus for measuring water and have been described in various publications and reports $[2,3]$. It is the purpose of this paper to give in one place the information that is needed for the effective use of the method; but the earlier paper contains material on some equipment and applications not included here, and should be consulted when special problems are encountered.

\subsection{General Method}

The measurement of water vapor in gases by observing the resistance of thin films of electrolyte has been employed occasionally at the National Bureau of Standards for a variety of purposes for nearly 40 years. The essentials of the method are extremely simple. A thin film of liquid, which may be such a material as phosphoric or sulfuric acid or a solution containing one or more acids, bases, or salts with a binding material such as gelatin or a high-polymer plastic, is spread over the surface of a solid insulator between metallic electrodes. The electrolyte tends to reach equilibrium with the water vapor in the atmosphere that surrounds it, and to form a solution the electrical resistance of which is a measure of the water vapor in the atmosphere. We need, in addition, some instrument for measuring or comparing electrical resistances and a means of calibrating the film by comparison with a gas of known moisture content. Polarization makes advisable the use of alternating current for the measurement.

The method was devised initially [4] to detect very small concentrations of water vapor in gases entering a catalytic reaction in which water is a poison. The material first tried for the conducting film was a salt, calcium chloride; but it was soon found that the salt became a nonconducting solid at a humidity far higher than that to be detected, and numerous

\footnotetext{
*Present address, Vitro Corp., Penns Gr)ve, N. J.
}

1 Figures in brackets indicate the literature references at the end of this paper. other electrolytes were tried. Among them phosphoric and sulfuric acids were found most useful because they served to detect the smallest concentrations of water vapor. However, films of these materials changed resistance so rapidly that it seemed hardly worthwhile to calibrate them by comparison with known atmospheres, laboriously prepared.

The method therefore fell into disuse except for qualitative work until F. W. Dunmore $[5,6]$ employed it successfully for much higher humidities in connection with meteorological observations. He used a salt, lithium chloride, as the electrolyte in a plastic film of very high resistivity, but one which held its calibration well. The Dunmore elements or modifications of them are used extensively in both meteorology and industry, and numerous independently developed resistance units of somewhat similar types have appeared [7]. The need during the war for a method of determining rapidly very small quantities of water vapor in aviator's oxygen led to the development of a means of calibrating a sensitive film at the time of its use so quickly and simply that little need remained for a permanent calibration. This at once greatly extended the possible applications of the method.

\subsection{Principle Involved in Calibration by the Adjustment of Pressure}

As a rough approximation, deviations from which will be discussed later, the resistance of a given film is independent of the gases other than water vapor with which it is in contact and depends only on the amount of water contained in unit volume. If a sample of gas, such as oxgyen or air, of known water content per unit volume, is passed over the film it will assume a certain resistance. If a second sample of gas of unknown water content is then passed over the film, the resistance will usually be different, but it may be restored to its original value by compressing or expanding the second sample until it contains the same quantity of water per unit volume (more exactly until the water vapor has the same fugacity) as the first sample. When this condition is reached, we note the pressure and readily compute what the water content would be in a unit volume at any other 
pressure (usually, but not always, 1 atm). If the unknown gas is initially at atmospheric pressure, it may be more convenient to change the pressure of the standard gas until the same resistance is produced by both.

As a simple illustration of the first procedure, let us say that the first sample of gas used as a standard is known to contain $2 \mathrm{mg}$ of water per liter, and that the second sample causes the detecting film to have the same resistance as the first (and that it therefore also contains $2 \mathrm{mg}$ of water per liter) when at a pressure of $100 \mathrm{~atm}$. If the second sample of gas is now expanded to 1 atm, it has about 100 times the volume but the same total quantity of water as before expansion, and the water content is, therefore, $0.02 \mathrm{mg} /$ liter. The second procedure may be illustrated by the following example. A cylinder of air known to contain $8 \mu \mathrm{g}(0.008 \mathrm{mg})$ of water per liter when expanded to atmospheric pressure was used as the standard gas. The resistance produced by exposing the film to a sample of Freon at atmospheric pressure was matched by adjusting the air to $18 \mathrm{psig}$ (pounds per square inch gage) or a total pressure of $2.2 \mathrm{~atm}$. Then the Freon at atmospheric pressure contained 2.2 times as much water as did the air at atmospheric pressure, or $18 \mu \mathrm{g} /$ liter.

Frequently it is convenient, in order to make the best use of available gages, to set one gas to an arbitrary pressure of no interest in itself and to match it by adjusting the pressure of the other For brevity, the process of adjusting the pressure of one or both gases to produce the same electrical resistance of the detector will be called comparing the gases. In general four pressures are involved in a comparison:

$P_{s}$, the pressure at which the standard gas contains a known concentration of water vapor, $S$.

$P_{c}$, the comparison pressure at which the standard gas is matched with the electrical resistance produced by the unknown gas at pressure $P_{x}$.

$P_{x}$, defined by the preceding statement.

$P_{w}$, the pressure at which we wish to know the concentration of water in the unknown gas.

The water content, $C$, of the standard gas at the comparison pressure is

$$
C=S \frac{P_{c}}{P_{s}} .
$$

Since it is known that the unknown gas has this same water content at the matching pressure $P_{x}$, the water content, $W_{x}$, at pressure $P_{w}$ of the unknown gas is derived from $C$, just as $C$ was derived from $S$ :

$$
W_{x}=C \frac{P_{w}}{P_{x}}=\frac{S P_{c} P_{w}}{P_{s} P_{x}} .
$$

Having determined the value of $W_{x}$ we can obviously use the newly analyzed gas as the standard to determine $W_{x_{1}}$, the water content of still another unknown gas at $P_{w_{1}}$ after matching it electrically at pressure $P_{x_{1}}$ against the new standard at $P_{w}$, thus:

$$
W_{x_{1}}=W_{x} \frac{P_{w_{1}}}{P_{x_{1}}}=S \frac{P_{c} P_{w} P_{w_{1}}}{P_{s} P_{x} P_{x_{1}}}
$$

There is obviously no limit to the number of steps of this kind that can be taken, but because some error is involved in each comparison, the results soon lose significance.

A gas that contains an approximately known concentration of water, to be used as the first or the only standard, can be obtained easily by saturating compressed air (or other compressed gas that may be available) with water vapor at any convenient pressure. $S$ then represents the concentration of water vapor in equilibrium with liquid water at the temperature of the measurement, and $P_{s}$ is the pressure in the saturator. $S$ and $W$ may be expressed in any units, not necessarily in micrograms per liter, pounds per thousand cubic feet, or other units of mass per unit of volume; they may also be expressed as partial pressures, relative humidities, or percent by volume. Since only ratios of pressures are involved in the computation of $W$ and $S$, any unit of pressure may be used, provided it is kept clearly in mind that total pressures are involved, not gage pressures (above atmospheric).

In the application of the method that has been most extensively made determining the moisture content of compressed gases - it is convenient to use as the standard gas air, oxygen, or nitrogen saturated at about 35 -atm pressure and expanded to $1 \mathrm{~atm}$. The water content of the unknown gas is to be determined at $1 \mathrm{~atm}$. Hence, if pressures are expressed in atmospheres, $P_{c}$ and $P_{w}$ of eq 2 are both unity, and the equation becomes

$$
W_{x}=\frac{S}{P_{s} P_{x}},
$$

in which $S$ is the concentration of water vapor in equilibrium with liquid water.

In the method of use described, the pressure gages are the measuring instruments. We are usually not at all concerned with the actual value of the electrical resistance of the sensitive film, and the electrical instruments are used only to show that two resistances, corresponding to messured pressures, are the same; but in some cases, especially when following changing concentrations of water vapor, it is impracticable to make a separate calibration through the adjustment of pressure for every variation of humidity, and readings of the electrical instruments are recorded and interpreted, usually by interpolation between values determined by pressure readings. The electrical circuit is then truly used as a measuring instrument and not merely as a null-point indicator.

In the foregoing description of principles, it was necessary to qualify many of the statements with the words about, approximate, etc. The corrections to be made to produce more accurate results and the sources of error will be discussed after the construction of the instrument and its operation have been described. 


\section{Description of Apparatus Employed}

\subsection{General Arrangement and Procedure}

The general method that has been outlined above may be employed with apparatus of great variety. For certain purposes the equipment may be designed for pressures either above or below atmospheric, and many of the parts may be made of glass, metal, or plastic in numerous arrangements. Several of these are described in reference [1] and will be omitted from this paper.

The essential electrodes, the separating insulation on which the conducting film is spread, and their support will be called collectively the detector; and the small tight enclosure in which the detecting surface is exposed to the gases is called the cell. The electrical equipment used for showing equality of resistance of the film under different conditions will be called the indicator. A simple arrangement for testing compressed gases is shown in figure 1. The

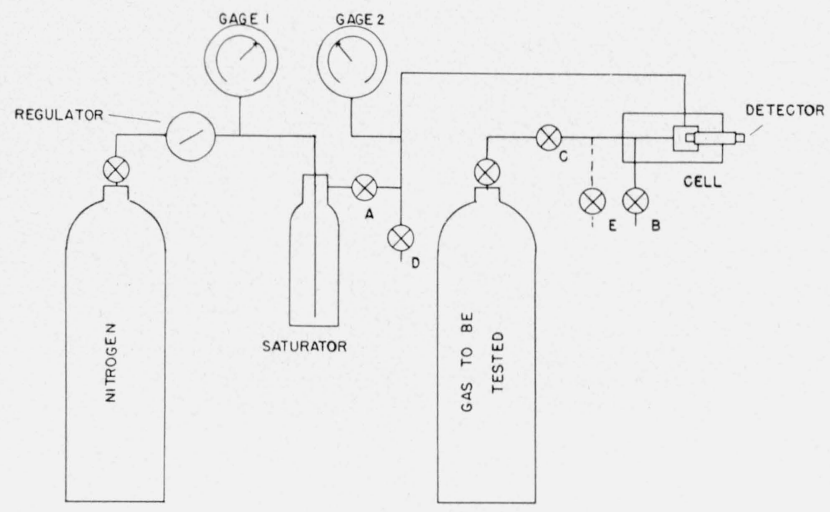

FIGURE 1. Diagram of mechanical connections for testing compressed gas.

regulator on the nitrogen cylinder is set to deliver gas to the saturator at a pressure of about 500 psi, as shown by gage 1. Nitrogen is suggested for this use because it will not corrode an ordinary steel cylinder if used as a saturator. Otherwise air or oxygen is just as good. The saturated gas is admitted in a slow stream to the cell through valve $A$ and, after passing over the detector, is discharged through valve $B$, which is generally left wide open. When the detector has reached equilibrium, the indicating circuit is adjusted so that the galvanometer needle is on scale and the reading is noted. The reading of gage 1 plus $1 \mathrm{~atm}$ is $P_{s}$ of eq 2 , and that of gage 2 with the same correction is $P_{c}$. In this case both $P_{c}$ and $P_{w}$ are $1 \mathrm{~atm}$, and eq 4 is substituted for eq 2 in the calculation of the water content. Valves A and $\mathrm{B}$ are then closed, and valve D is opened. The gas to be tested is admitted at a moderate rate of flow through valve $\mathbb{C}$, and valve $D$ is closed until the galvanometer balances at the point previously noted. The reading of gage 2 plus $1 \mathrm{~atm}$ is entered in eq 4 as $P_{x}$, and the equation is complete.
In the arrangement illustrated, slight leakage of gas through valves $\mathrm{A}$ or $\mathrm{C}$, which it is hard to avoid with complete certainty, does not affect the result, because in each case the leaking gas is discharged without reaching the detector. If only one cylinder of gas is to be tested, it may first be attached to the saturator to provide the standard gas and then connected as the gas to be tested. If a high-pressure regulator is not available and gage 1 has a sufficient range, the full pressure of the cylinder may be applied to the saturator, but this ultimately results in the waste of compressed gas and a certain amount of inconvenience or a reduced accuracy in the reading of pressures.

At present, the arrangement diagrammed in figure 2 is used for more accurate work in the labora-

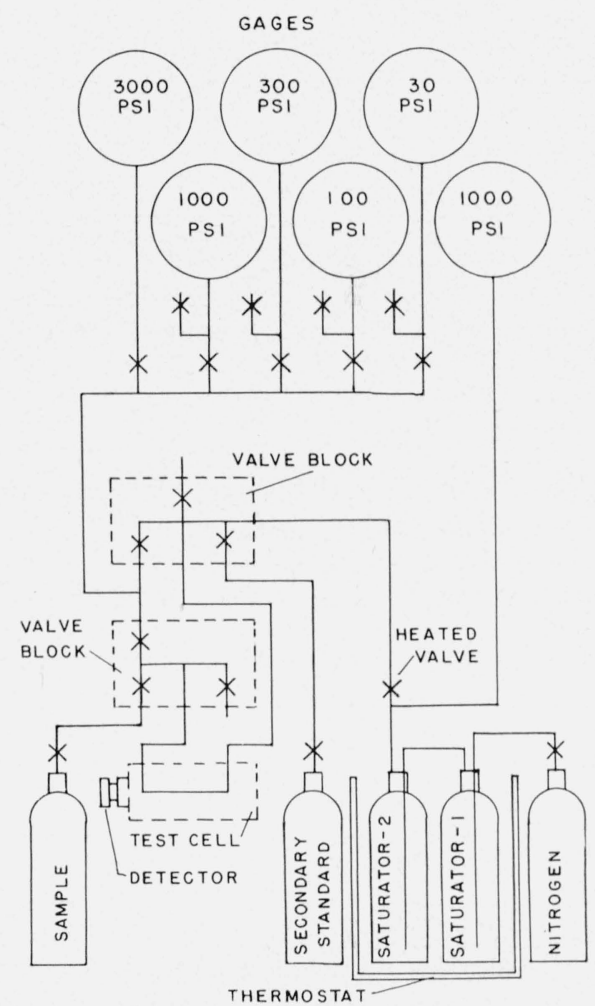

Figure 2. Diagram of mechanical connections for very accurate testing of compressed gases.

tory. The two-stage saturator reduces the degree of uncertainty that saturation is complete at the indicated temperature, especially if the bottles are immersed in a thermostated oil bath. The bank of pressure gages covering the five ranges shown in the figure permits pressures to be read with accuracy in any part of the range.

The arrangement of a portable model of the instrument is shown in figure 3 . The valves are lettered as in figure 1. A spare valve, E, connecting to the system at the same point as valve $\mathrm{C}$, is not needed for the testing of gas for compliance with Army-Navy specifications, but is very convenient 

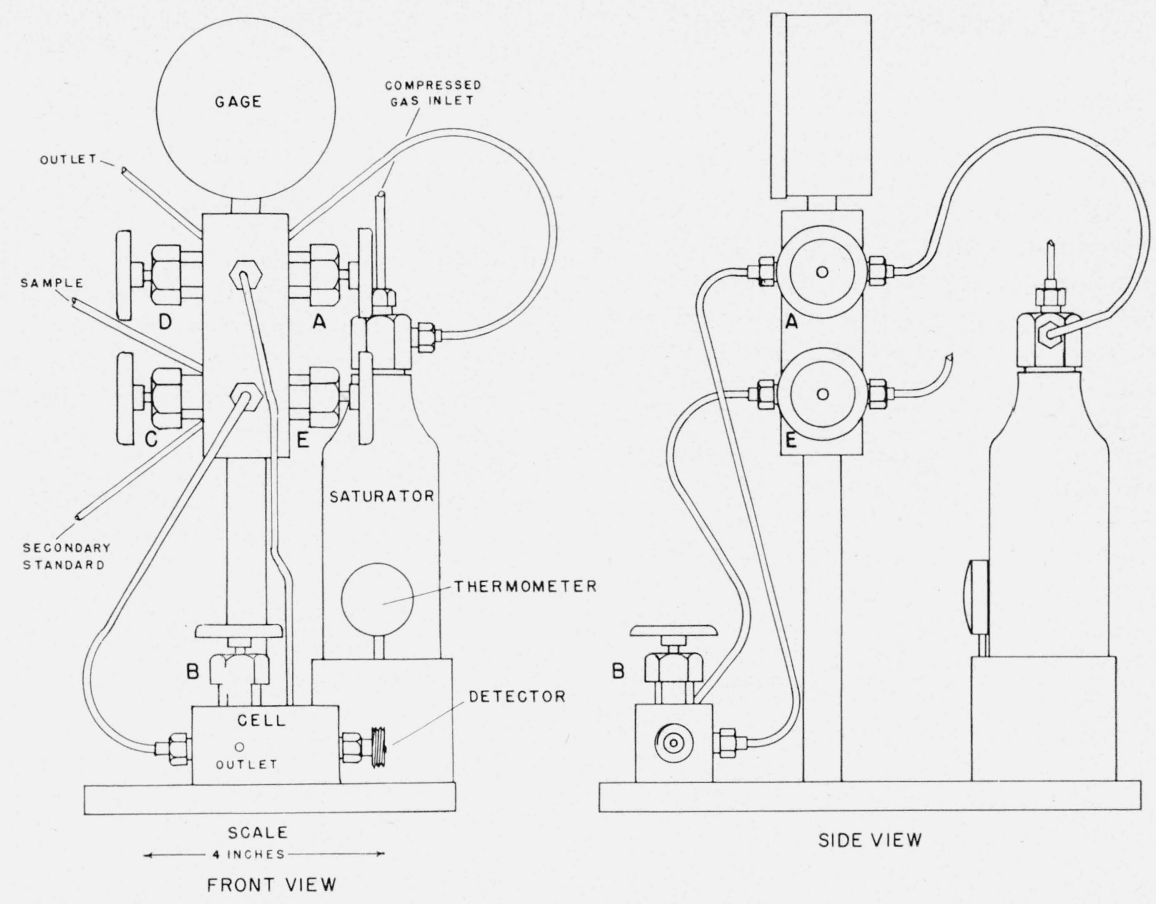

Figure 3. Front and side elevation of portable instrument.

in other work either for the attachment of a pressure gage more sensitive than "gage 2 " or for introducing' a "secondary standard" gas that is drier than can be obtained from the saturator with gas at any available pressure.

Four of the valves were mounted in a single valve block for simplicity of support. Further details are shown in cross section in figure 4 . The block is made of heavy metal to conduct heat as readily as possible to the points of expansion of the gas through the principal valves. The cell is connected to the valve block only through considerable lengths of small metal tubing to minimize the effects of expansion on the temperature of the detector. Valve $\mathrm{B}$ is placed directly on the cell to minimize the pressure drop from detector to outlet when the standard gas is to be used at $1 \mathrm{~atm}$ without measurement or corrections. It is quick-opening, and its passages are large for the same reason.

Several instruments of this design were made in 1943 and supplied to stations of the Armed Forces. One of these was used to test 56,000 cylinders without repair except the replacement of the detector; and at least one is still in occasional use. Tests for compliance with the specified limit of $20 \mu \mathrm{g}$ of water per liter in aviators oxygen were routinely made with one instrument at the rate of 100 per hr. A precision of about $\pm 0.2 \mu \mathrm{g}$ /liter, roughtly 2 parts per 10 million by volume is obtainable at the specified limit if care is taken, and only 100 or $200 \mathrm{ml}$ of gas need be expended per test.

Details of construction of the various parts will now be discussed.

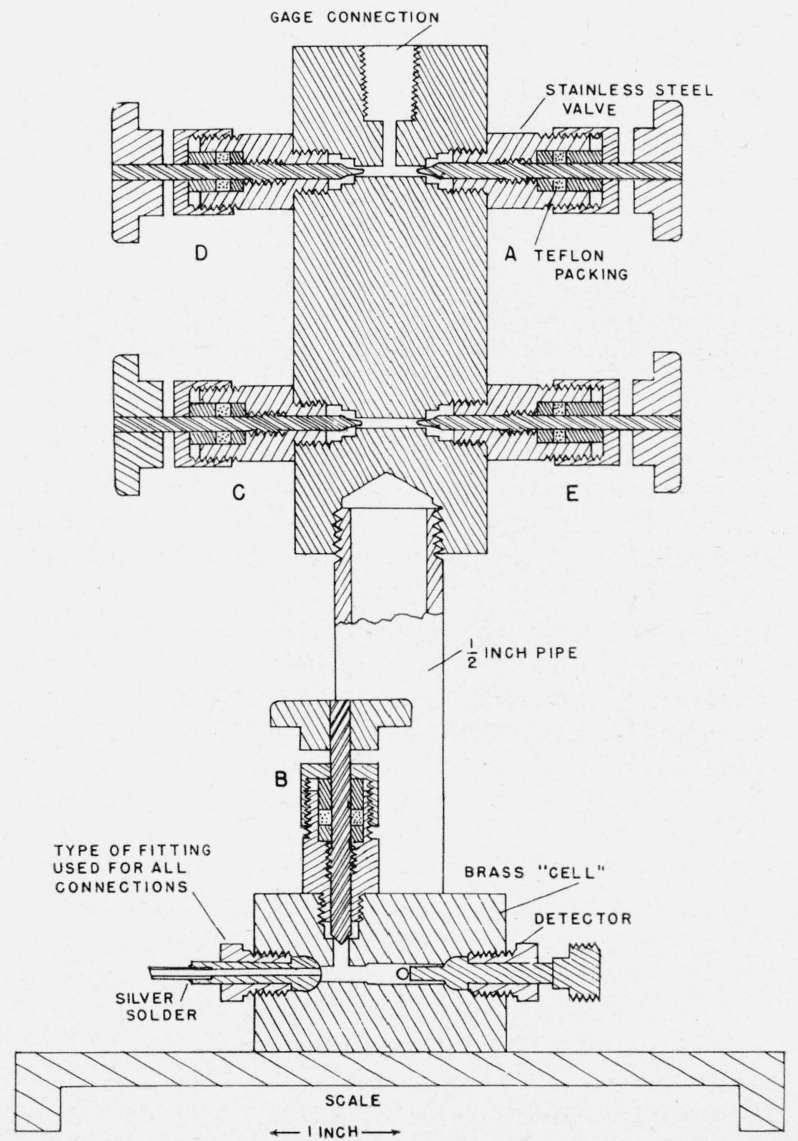

Figure 4. Section of valve block and cell block of portable instrument. 


\subsection{Detector \\ a. Detector Currently Used}

In figure 5 is shown the detector preferred by the authors because of its compactness and ease of handling when recoating or transferring from a place of use to a cell for calibration, and also because it can withstand repeated pressures up to 6,000 psi without developing cracks in the glass insulation. Unless otherwise specified, it may be considered to be the detector referred to throughout the remainder of this paper. A central electrode is made by filling a piece of small thin-walled platinum tubing with "French sealing-in glass" and goldsoldering a platinum wire to one end. The outside diameter of the tube should not exceed $1 \mathrm{~mm}$, and its wall thickness is preferably kept below one-tenth of the diameter. The outer electrode is a platinum tube about $3 \mathrm{~mm}$ in outside diameter with a similarly low ratio of wall thickness to diameter. Platinum is wet readily by the molten glass used, and clear beads of it should be allowed to flow into the tubes by capillarity rather than forced into place. Otherwise a film of air may be trapped between glass and metal. Nickel is preferred for the detector body because it has a sufficiently high melting point and can be goldsoldered to platinum more readily than can stainless steel.

Heating must be controlled rather carefully to a temperature between that at which the glass flows freely and that at which it begins to decompose with the formation of bubbles. Cooling should be done slowly in a glass-blower's lehr. If the glass cracks or separates from the metal during construction or use it is very difficult to repair because air is likely to be trapped during resealing.

The materials and precautions described are needed to make a detector that will withstand high and rapidly changing compressive stresses. Glass and metal do not have exactly the same modulus under compression and separate quickly if a flaw develops. If pressures during use do not exceed a few hundred pounds per square inch, a durable detector is rather easily made; but rapid changes from 100 to $400 \mathrm{~atm}$ (the highest pressure at which detectors have been regularly used) cause early failure unless the detectors are extremely well made.

The platinum wire from the inner end of the center electrode leads through the nickel shaft to a specially designed terminal for connection to an Amphenol cable. The wire is shielded from contact with the shaft by a small plastic tube, is threaded through a Teflon disk that fits into a recess in the terminal head, and is soldered to a small brass insert in the Teflon. A loosely fitting $3 / 8$-in. sleevenut, 24 threads per in., placed on the shaft before the head is screwed into place serves to attach the detector to the cell.

After assembling, the end of the detector is ground to expose the electrodes in a surface that need not be polished but should be without irregularities visible to the unaided eye. The dull finish left by grinding with abrasive grains $20 \mu$ in diameter seems to be about right.

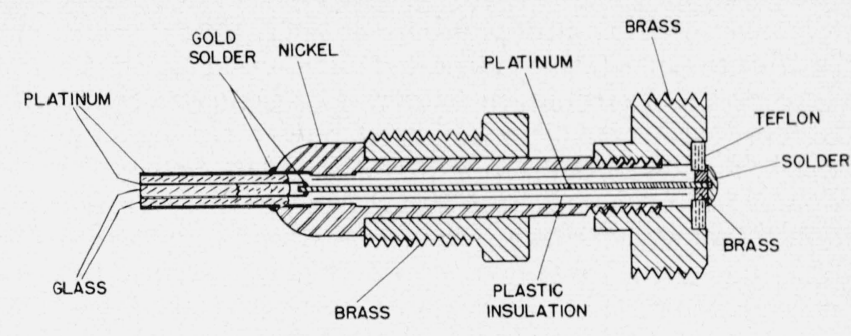

Figure 5. Detail of detector.

\subsection{Electrical Indicator}

Two indicating circuits are shown in figures 6 and 7 . They differ in two respects. In the first, and less expensive circuit, the primary bridge is composed of the detector and three resistances each of $1 \mathrm{meg}$; and the output of the twin triode is used in a second bridge of which the slidewire $R_{4}$ constitutes two arms. In the more elaborate circuit, two of the 1-meg resistors of the primary bridge have been replaced by 400-mh inductances with apparent but slight improvements in performance. The slidewire $R_{4}$ of figure 6 has been replaced by a fixed resistance and a resistance box. The two modifications of the cir-

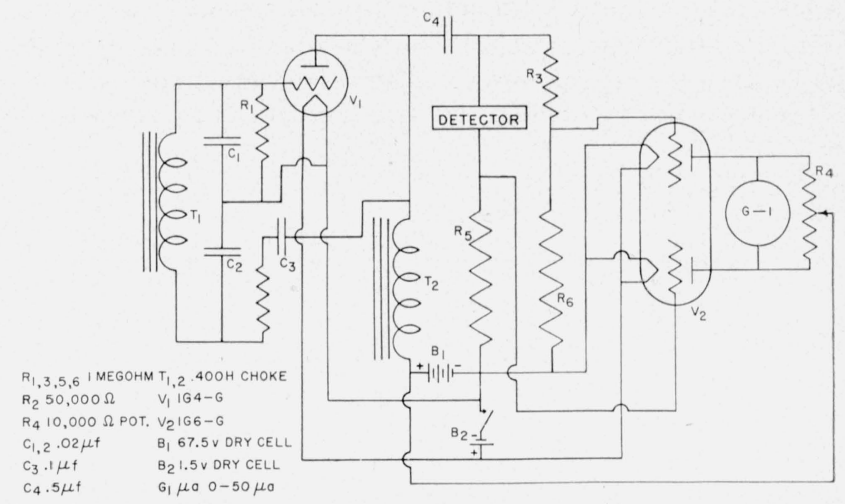

Figure 6. Diagram of indicating cirucit used when gages are employed as primary measuring instruments.

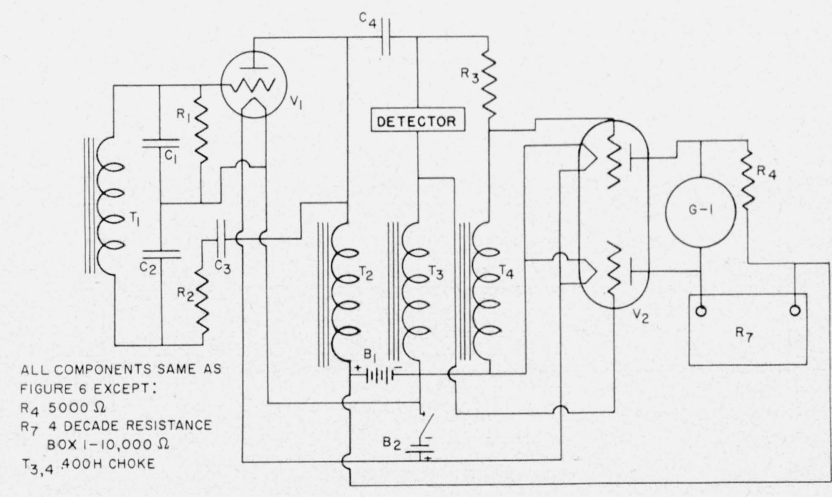

Figure 7. Diagram of measuring circuit used when measurements depend on electrical calibration. 
cuit are entirely independent of each other, and any combination of the different elements can be used. Two or three circuits in which batteries were replaced by 60 -cycle alternating-current power have also been used, but they lack the portability of the batteryoperated indicator and have otherwise been somewhat less satisfactory. For continuous operation at one place, the batteries could without doubt be replaced by suitable direct-current power supplies derived from the alternating power line.

In both the circuits illustrated, the twin-electrode vacuum tube supplies pulsating direct current to two branches of a circuit. The "galvanometer" (usually a microammeter) connects these two branches and, with the resistors in each branch, operates like the galvanometer and two branches of an ordinary Wheatstone bridge.

In the use of the indicating circuit of figure 6 , the contact on resistance $R_{4}$ is simply adjusted until the galvanometer reading is brought to a convenient point of the scale, which need not be zero, and this reading is noted and reproduced in subsequent "comparisons." In this use of the indicator, the electrical instruments are simply used to show a common null point, and the actual measurements are made with the pressure gages.

The second circuit permits the electrical resistance of the detector to be measured with moderate accuracy and is employed when for any reason the electrical equipment, rather than a combination of pressure gages, is to be used as the measuring instrument. It was used in studies of the equilibrium resistance

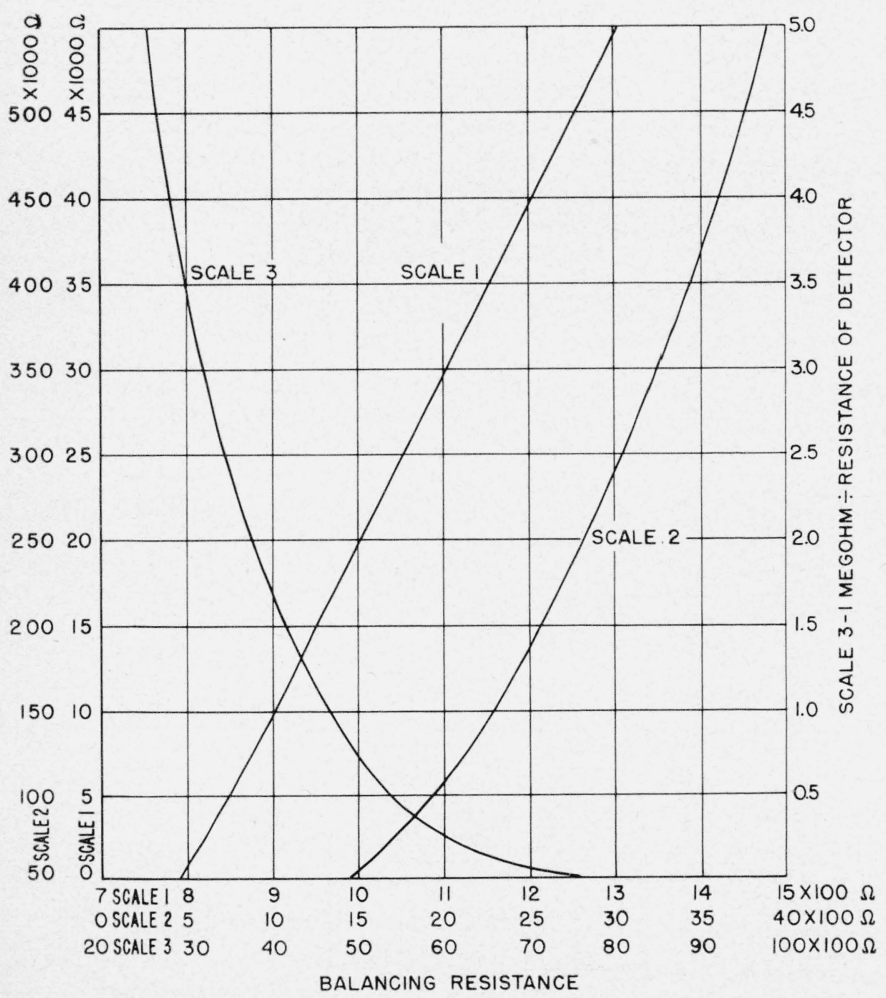

Figure 8. Calibration of measuring circuit in terms of resistance of detector. of films, the rate of attainment of equilibrium, etc., and is frequently useful for interpolating between indications of the standard, particularly when rapid changes of humidity are being followed.

The characteristics of the electrical indicator as a whole are shown for the circuit of figure 7 by the calibration curves of figure 8 . The galvanometer used had a resistance of $123 \mathrm{ohms}$ and a range of $15 \mu$. The variable resistance, $R_{7}$, was a plug-box of $10,000 \mathrm{ohms}$ in steps of $0.1 \mathrm{ohm}$. The three curves in the figure, with their corresponding scales, show resistances of the detector and corresponding values of the variable resistance, $R_{7}$, required to bring the galvanometer to balance. The calibration was made by replacing the detector with successive measured fixed resistances. The entire range of possible resistances from short circuit to open circuit is covered. The higher resistances are plotted on a reciprocal scale.

\subsection{Saturator}

The saturator shown diagramatically in figure 9 is the type generally used. Saturators with more elaborate packing have not worked as well. The sand used in filling the saturator does not have to meet accurately the specifications given in the figure. Gravel of larger size will do as well. When the water level was kept as low as shown, no trouble has been encountered with spray from cylinders filled in this way, even when the rate of flow of gas was much greater than needed.

A single saturator leaves much to be desired. The sand has a high heat capacity, and with cooling from evaporation at the bottom and changing temperature

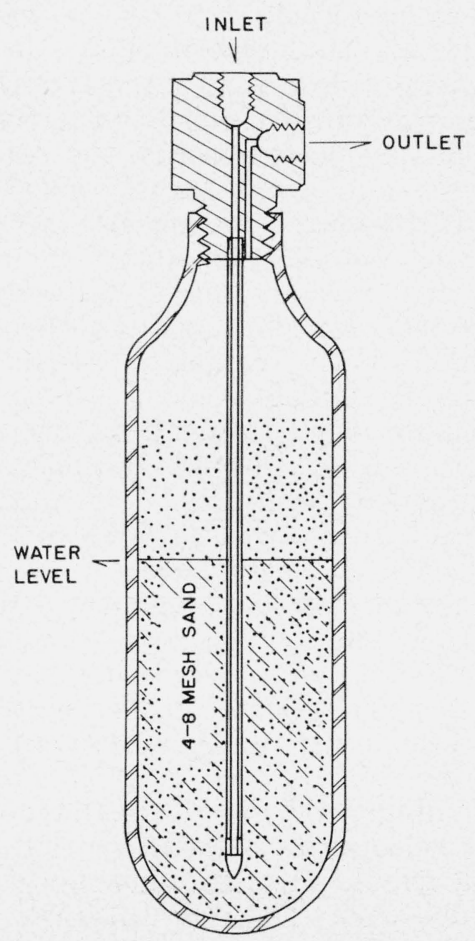

Figure 9. Saturator. 
in the surroundings, the actual temperature of saturation is uncertain. For highly accurate results, a double saturator and trap, shown schematically in figure 10 , immersed in a bath of oil or other convenient liquid is to be preferred.

In the series of cylinders shown in figure 10, the first cylinder has enough capacity to retain all the water in all three cylinders and its function is to guard against flooding other parts of the apparatus if mistakes are made in the manipulation of valves when gas at very high pressure is being tested. The second cylinder is the principal saturator. The third cylinder serves both as an additional spray catcher and as a final saturator when continuous evaporation in the middle cylinder results in appreciable cooling. The bath may be thermostated for precise work, but it is ordinarily necessary only to read a thermometer immersed in the bath liquid. In the most exacting work, also, it may be desirable to warm the outlet valve to prevent cooling and condensation by expansion at that point, but this is ordinarily unnecessary because of the heat capacity of the valve and the small volume of gas expanded through it. The valve must not be colder than the saturator, of course.

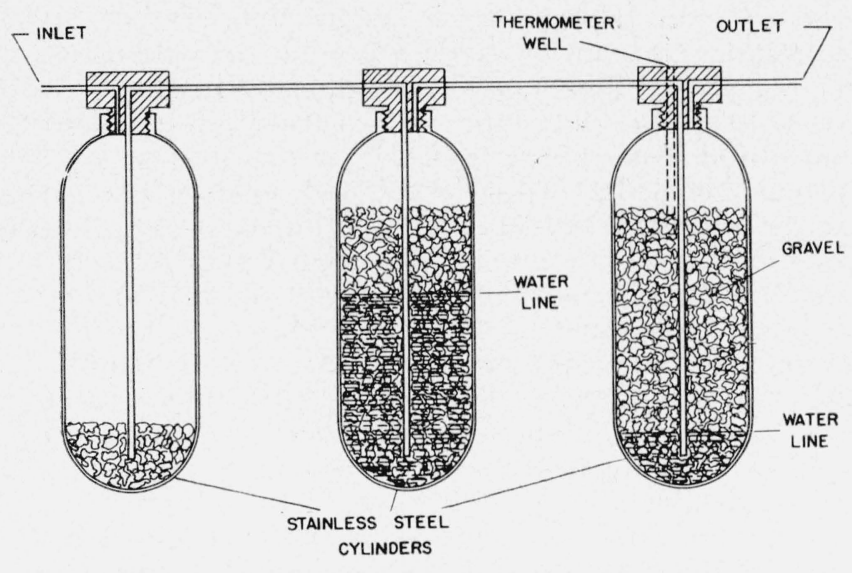

FiguRE 10. Double saturator and trap.

\subsection{Valves, Connections, Gages, Regulators}

Accurately made needle valves of the simple construction shown in figure 11 have been mostly used. Valves of other types that have been tried have been no more satisfactory at the best. Because they may at times get wet, and they must not corrode, ordinary steel should not be used for either valve stem or valve body. Good results have been obtained with stainless steel needle valves with bodies of brass or a softer stainless steel that will not score in contact with the needle.

The packing of the valves is very important. Teflon, a polymer of tetrafluoroethylene, is a suitable packing material. It is not wet by water, offers little friction on the valve stem, is easily machined or molded to an exact fit, has enough elasticity to remain tight when compressed, and can be heated to well above the boiling point of water without damage when the apparatus is being dried out.
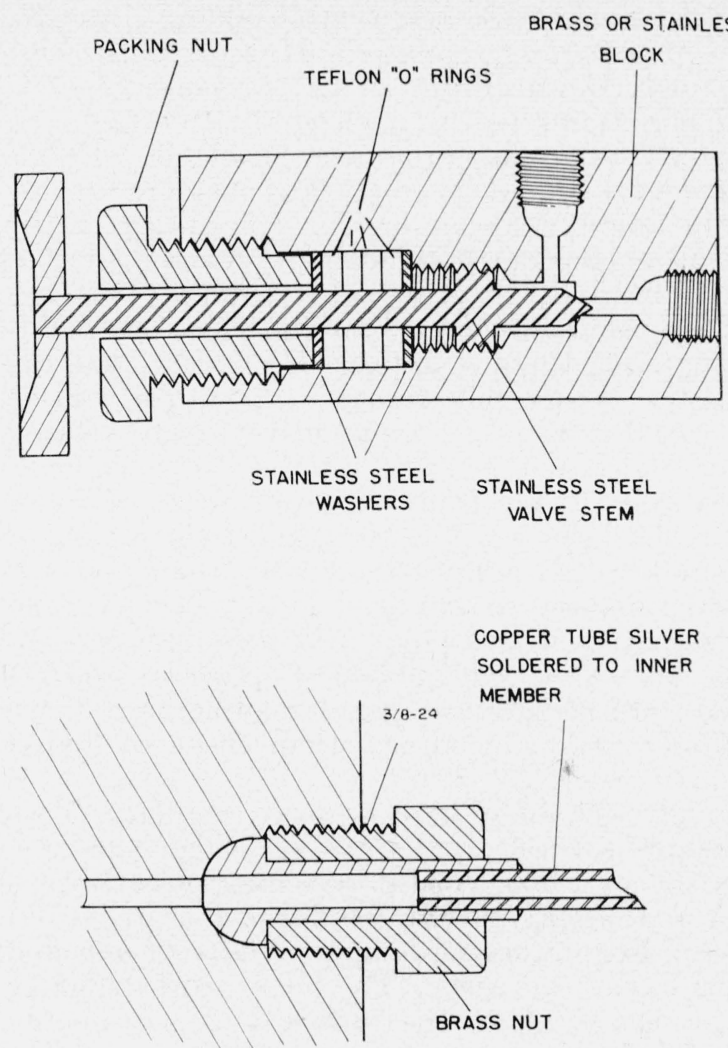

Figure 11. Needle valve and connector.

The apparatus should be easy to take apart completely for drying, and easy to reassemble. The connecting fittings shown also in figure 11 have been particularly satisfactory; they are simple, rugged, and easy to make tight. Only metal-to-metal joints should be considered. Threads, tapered or otherwise, cannot be made tight without a vast amount of trouble; fiber washers and other forms of packing are as bad or worse, chiefly because they retain water.

If threaded couplings only are available one piece can be "tinned" thinly with solder. When connected, the mating piece cuts a new thread in the solder and is tight until the joint is broken, but it is difficult to take apart and will not remain tight after many separations.

In making up the assembly of valves and connections, every precaution must be taken to eliminate places where water can be stored by such things as hygroscopic salts, rubber, or rust (which is a good adsorbent and acts much like a little silica gel). Soldering flux is particularly bad, and capillary spaces such as screw threads can be troublesome. It is good practice before final assembly of the equipment to wash the parts with a solvent for grease and then to boil them for several hours with several changes of water to remove hygroscopic salts. Finally, the parts are dried in an oven.

Gages of the Bourdon type have been used exclusively for work involving pressures above atmos- 
pheric. In some work below atmospheric pressure, mercury manometers were used. If care is taken with other things, the accuracy of the pressure gages is the limiting factor in the accuracy with which the method can be applied to most problems. Hence the gages used should be as good as it is practicable to obtain unless a lower degree of accuracy in the final result is considered sufficient. In the testing of oxygen, it is frequently desirable to apply the full pressure of the cylinder to the cell. Even when this is not the case, there is always the chance that the full pressure, sometimes as high as $2,640 \mathrm{psi}$, will be applied accidentally. Consequently, a gage reading to 3,000 psi should be used on the cell. There is generally less trouble from obscure sources of water if the standard gas is not too dry, hence the saturator is seldom kept at a pressure higher than 500 psi, and a gage reading to 500 or at most 1,000 psi is all that is required at this point. If only high concentrations of water, say above 1 percent relative humidity, are of interest, gages reading to $200 \mathrm{psi}$ will afford greater accuracy than those of higher range.

Although lack of a high-pressure regulator does not preclude saturating the gas at a high pressure, such as 500 or 1,000 psi, by attaching directly to a cylinder at that pressure, a regulator is a great convenience. Regulators with upper limits of 500 and 1,000 psi have been used. The latter works slightly better at 500 psi than the former and is probably the more desirable for general use.

\section{Conducting Films}

\subsection{Composition of the Film}

The film recommended for use in most work is a mixture of phosphoric and sulfuric acids. A drop or two of concentrated sulfuric acid added to a small lump of phosphorus pentoxide or to several drops of concentrated phosphoric acid will serve to produce detecting films for weeks of use. The proportions of the acids are not important. Phosphoric acid alone is to be preferred except for rather dry gases. It behaves irregularly at humidities of less than about $8 \mu \mathrm{g} /$ liter, probably because of the formation of metaphosphoric acid or other solid phase. This erratic behavior has never been observed in the presence of an appreciable fraction of sulfuric acid, but the phosphoric acid coating disappears less rapidly than sulfuric acid, probably because it is less volatile.

No film of either or both acids remains stable very long. Resistance always increases either because the acids evaporate or because they react with their supporting materials or with neutralizing gases in the atmosphere. Usually they do not change appreciably during a half hour, and a single comparison with a standard can be used that long if temperature is constant; but, unless the detector has to be so located that it is not accessible for comparison, it is easier to make a calibrating comparison with each reading than to control or keep track of temperature changes, and the regular checking of each reading leads to more certain results. A film usually retains its sensitivity well enough for use, when regularly compared with the standard, for a half day.

At least a part of the acid that is lost from the detecting film dissolves in the supporting glass. After a few days the glass becomes conducting; it comes to equilibrium with the atmosphere very slowly; and the result is that readings, which should become nearly constant in a few seconds after a change of humidity, change promptly to a nearly constant value and then drift endlessly at a slow rate. To avoid this difficulty it is necessary to remove the contaminated surface of the glass. This can be done by rubbing the detector surface several times across a drop of glycerine and fine abrasive on a hard surface (a microscope slide is suitable). If this is done daily only a few seconds of grinding will suffice to keep the detector in good condition. To minimize reaction between acid and glass, it is worthwhile to rinse the detecting surface with water and wipe dry when the detector is not to be used even for an hour.

A large number of experiments have been made by the authors and others with films containing hygroscopic salts in various media. These have had several objects, (1) to obtain films that always have the same resistance at the same temperature and humidity and can be given a permanent calibration, (2) to obtain films the calibration of which will not be altered by exposure to a saturated or nearly saturated atmosphere, and (3) to measure water in atmospheres that would react with acids. The first fairly successful detectors containing salts were those prepared by Dunmore $[5,6]$ which have been commercially produced and extensively used in meteorological and industrial work since about 1940. Their properties have been gradually improved or modified for various purposes [7]. One of the more recent ones, especially adapted to the conditions of measurement in the upper atmosphere, is that of Wexler and associates [8].

The Dunmore elements and most of the others require long and careful "conditioning" before they are calibrated and used; and they must be protected from long exposures to very wet or very dry gases. For some purposes solutions of salts in glycerine or glycerine and gelatin can be used satisfactorily, without prior aging, on the detector ordinarily used with phosphoric and sulfuric acids [1, pp. 186-9].

\subsection{Application of the Film}

Films of sulfuric and phosphoric acid of ample sensitivity are thin enough and viscous enough to require no binder unless they are exposed for more than a few seconds to humidities very near to saturation. The detector is coated simply by touching a stick, such as a toothpick, to the acid and then to the detecting surface, and wiping off the excess acid with a bit of cotton. Less than a minute is usually required. One soon learns about how much to rub off. Wiping with a moderate pressure on three successive clean portions of the cotton is one rule of thumb. Another is to wipe until the finely ground glass surface appears dull but not quite dry. If 
greater accuracy is desired, the adjustable resistances of the indicator can be set to approximately the desired reading in room air and the coating wiped off with one light touch of the cotton after another until the swing of the galvanometer needle shows that the resistance has become higher than corresponds to electrical balance.

Fortunately, the thickness of the film is not at all critical. One film may have several times the resistance of another, but their difference be hardly noticeable in use. In some ranges of humidity, it is quite possible to use interchangeably films having a ratio of resistances of 50:1. In general, a thicker film permits greater sensitivity, and a thinner one reaches equilibrium more rapidly. The rule is, therefore, to use as thin a film as will have the desired sensitivity.

\subsection{Sensitivity}

The actual resistance of a single phosphoric acid film, film $\mathrm{A}$, over almost the whole range of humidities was measured with the circuit of figure 7 . The observed data are given in table 1 and represented

TABLE 1. Resistance of a film of phosphoric acid (A) at various concentrations of water vapor

\begin{tabular}{|c|c|c|c|c|c|c|}
\hline \multirow{2}{*}{$\begin{array}{l}\text { Balane- } \\
\text { ing } \\
\text { resist- } \\
\text { ance }\end{array}$} & \multirow{2}{*}{$\begin{array}{l}\text { Resistance } \\
\text { of detector }\end{array}$} & \multicolumn{5}{|c|}{ Concentration of water } \\
\hline & & $\begin{array}{l}\mu \mathrm{g} \text { per } \\
\text { liter a }\end{array}$ & $\begin{array}{l}\text { Relative } \\
\text { humidi- } \\
\text { ty at }\end{array}$ & $\begin{array}{c}\text { Partial } \\
\text { pres- } \\
\text { sure }\end{array}$ & Approx & $\begin{array}{l}\text { nate dew } \\
\text { nt }\end{array}$ \\
\hline $\begin{array}{l}\text { Ohms } \\
5,730 \\
5,664 \\
5,541 \\
5,540 \\
5,167\end{array}$ & $\begin{array}{l}\text { Ohms } \\
2,870 \times 10^{3} \\
2,700 \\
2,390 \\
2,050 \\
1,600\end{array}$ & $\begin{array}{l}11.3 \\
22.0 \\
35.2 \\
56.4 \\
86.9\end{array}$ & $\begin{array}{c}\text { Percent } \\
0.039 \\
.076 \\
.12 \\
.19 \\
.30\end{array}$ & $\begin{array}{c}m m H g \\
0.011 \\
.021 \\
.034 \\
.055 \\
.084\end{array}$ & $\begin{array}{l}\circ C \\
-74 \\
-53 \\
-49 \\
-45 \\
-41\end{array}$ & $\begin{array}{r}\circ F \\
-101 \\
-63 \\
-56 \\
-47 \\
-42\end{array}$ \\
\hline $\begin{array}{l}4,913 \\
4,700 \\
4,320 \\
3,836 \\
3,420\end{array}$ & $\begin{array}{r}1,280 \\
1,040 \\
720 \\
528 \\
394\end{array}$ & $\begin{array}{l}138 \\
171 \\
263 \\
411 \\
563\end{array}$ & $\begin{array}{r}.48 \\
.59 \\
.91 \\
1.4 \\
1.9\end{array}$ & $\begin{array}{l}.13 \\
.17 \\
.26 \\
.40 \\
.55\end{array}$ & $\begin{array}{l}-38 \\
-35 \\
-30 \\
-26.7 \\
-23.5\end{array}$ & $\begin{array}{l}-36 \\
-31 \\
-22 \\
-16.2 \\
-10.3\end{array}$ \\
\hline $\begin{array}{l}3,195 \\
3,174 \\
2,955 \\
2,830 \\
2,304\end{array}$ & $\begin{array}{l}337 \\
332 \\
280 \\
253 \\
154\end{array}$ & $\begin{array}{r}655 \\
655 \\
790 \\
879 \\
1,520\end{array}$ & $\begin{array}{l}2.3 \\
2.3 \\
2.7 \\
3 \\
5.2\end{array}$ & $\begin{array}{r}.64 \\
.64 \\
.77 \\
.85 \\
1.48\end{array}$ & $\begin{array}{l}-22 \\
-22 \\
-20 \\
-19 \\
-13.1\end{array}$ & $\begin{array}{l}-7.6 \\
-7.6 \\
-4 \\
-2.2 \\
+9.4\end{array}$ \\
\hline $\begin{array}{r}1,980 \\
1,825 \\
1,420 \\
1,177 \\
973\end{array}$ & $\begin{array}{r}106 \\
88 \\
50 \\
37 \\
17\end{array}$ & $\begin{array}{r}2,170 \\
2,600 \\
4,510 \\
7,220 \\
13,200\end{array}$ & $\begin{array}{c}7.5 \\
9 \\
15.6 \\
24.9 \\
45.5\end{array}$ & $\begin{array}{r}2.11 \\
2.53 \\
4.38 \\
7.01 \\
12.8\end{array}$ & $\begin{array}{l}-9.1 \\
-7 \\
-0.5 \\
+6 \\
15\end{array}$ & $\begin{array}{l}15.6 \\
19.4 \\
31.1 \\
42.8 \\
59\end{array}$ \\
\hline $\begin{array}{r}886 \\
790 \\
7,814\end{array}$ & $\begin{array}{l}8 \\
0 \\
\infty\end{array}$ & $\begin{array}{r}20,800 \\
\text { (b) } \\
\text { (c) }\end{array}$ & $\begin{array}{c}71.7 \\
-\cdots \\
-\cdots\end{array}$ & $\begin{array}{c}20.2 \\
--.\end{array}$ & $\begin{array}{l}22.3 \\
--.\end{array}$ & $\begin{array}{r}72.2 \\
- \\
-\end{array}$ \\
\hline
\end{tabular}

a To obtain parts per million by volume, multiply micrograms per liter by 0.804 . To obtain parts per million of air by weight, multiply by 0.62 .

b Short circuit. o Open circuit.

by curve 1 of figure 12 . The concentration of water in micrograms per liter is plotted on a logarithmic scale with respect to the balancing resistance (resistance $R_{7}$ of fig. 7 ) on a linear scale. The approximate resistance of the film itself is plotted on a logarithmic scale with respect to the same ordinate in curve 2 , the data for which were taken from curve 1 and the calibration of figure 8. Film A was such as would ordinarily be used in the lower part of the range accessible to phosphoric acid. For humidities in the higher range, a thinner film is preferable because it reaches equilibrium with the atmosphere more

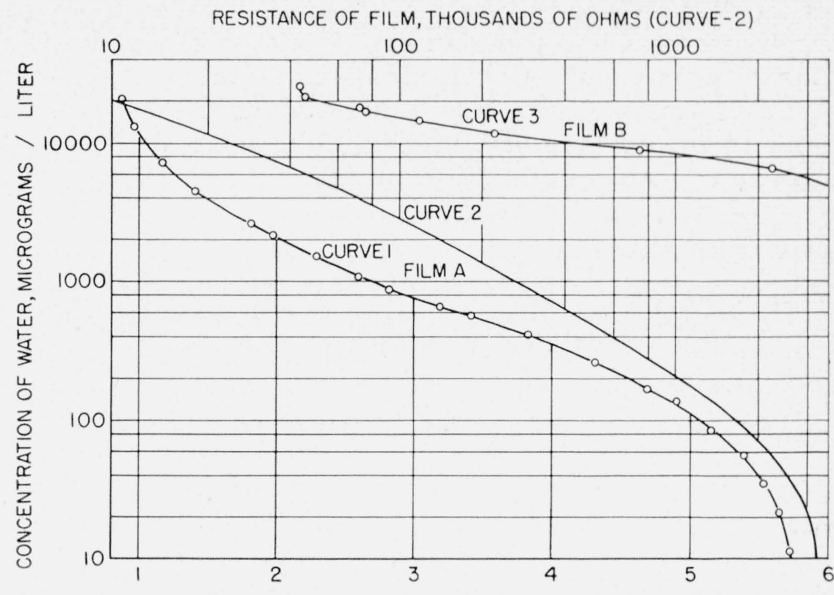

BALANCING RESISTANCE, THOUSANDS OF OHMS (CURVES I AND 3)

Figure 12. Calibration of two conducting films in terms of concentration of water.

quickly and does not begin to flow at so low a humidity. A typical application of phosphoric acid for this purpose, film B, is represented by curve 3, drawn on the same scale as curve 1. One film has about 20 times the resistance of the other, but both are readily usable over most of the range of humidities. In figure 13, the balancing resistances are plotted with respect to relative humidity. The two films were used at different temperatures of $83.6^{\circ}$ and $81^{\circ} \mathrm{F}$, hence, the ratios of weights per unit volume and of relative humidities are not the same. The resistance of film $B$ reached a minimum before a relative humidity of 100 percent was reached, and

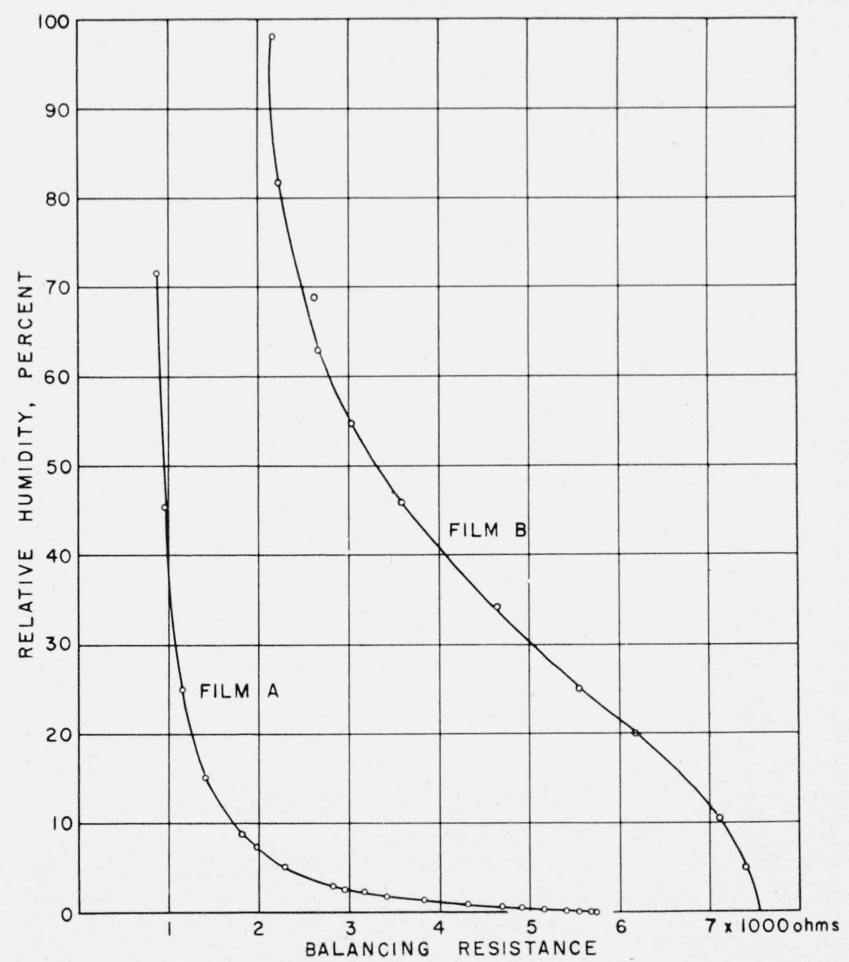

Figure 13. Calibration of two conducting films in terms of relative humidity. 
the hook on the upper end of curve 3 of figure 12 represents a real effect. During exposure to the highest humidity observed with film A, its resistance passed through a minimum (which was the resistance recorded) and was increasing when the experiment was discontinued. In both cases the effects noted were probably caused by flow of the too mobile solutions formed as saturation was approached.

The sensitivity of the electrical indicator of figure 7 with film $\mathrm{A}$ is shown by figure 14 . The curves were derived as follows. It was assumed that the balancing resistance could be read to 0.05 percent of its magnitude at any point. This corresponds to about 0.8 scale division of the galvanometer. The sensitivity, by which is meant the change in concentration of water that could be observed with the instrument, was assumed to have the same ratio to the difference between two observed humidities as the 0.05 percent of the mean balancing resistance had to the difference between balancing resistances, and this sensitivity was plotted with respect to the average of the two observed humidities. It is apparent at once that the sensitivity approaches about $0.3 \mu \mathrm{g} /$ liter or 0.1 percent of the water present, whichever is greater.

Figure 14 indicates instrumental sensitivity only. It must not be supposed that an absolute accuracy as great as this is usually or ever obtainable. The effects of all other sources of uncertainty remain to be accounted for. Actually, electrical sensitivities, in the lower range of humidities at least, can be considerably increased by using thicker films or by substituting an electronic null-point indicator for the galvanometer, but at present there is usually no object in doing so, chiefly because sufficiently accurate adjustment and readings of pressure cannot be made. Higher sensitivities in terms of the ratio of water vapor to total gas (or of weight per unit volume of expanded gas) are readily obtainable when

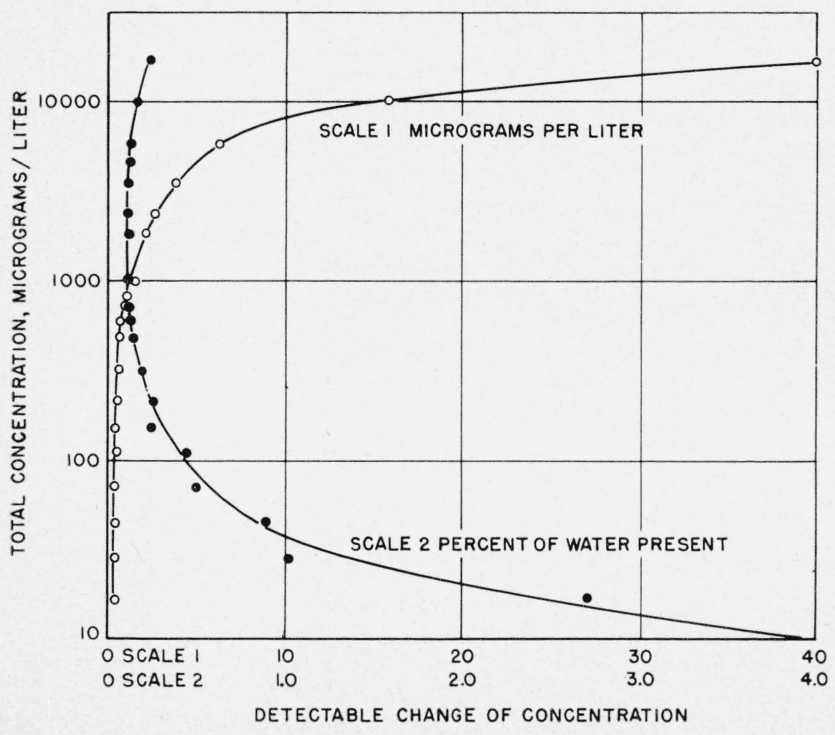

FIGURE 14. Sensitivity of typical phosphoric acid film. the gas to be measured is under high pressure, and they are occasionally useful.

\subsection{Speed of Response}

The greatest improvement made in technique since the publication of [1] was the result of experiments reported in that paper on the rate at which equilibrium is attained between the detector and the atmosphere to which it is exposed. Those experiments indicated that the acid dissolved in the glass insulator, producing a thin, sligbtly conducting, and slowly changing layer beneath the fast-acting surface coating. When the contaminated glass has been removed by surface grinding and an acid film of ordinary thickness has been applied, 90 percent of the change of resistance resulting from a change of atmosphere occurs within a second or two. A more precise determination of lag is difficult to make because it is not easy either to specify the thickness of film used or to provide an instantaneous change of atmosphere.

The grinding (or honing) of the detector surface was previously described. When it has been properly done, there is almost no drifting of the electrical reading when the detecting surface is in an atmosphere of constant humidity. When the detector is exposed to the air of an occupied room, the needle of the indicator waves like a flag in a breeze because it is following the different humidities always encountered in the fluctuating air currents in such a room.

\section{Procedures, Corrections, and Sources of Error}

\subsection{Operation of the Instrument}

\section{a. Procedure in Testing Compressed Gas}

The method of operating the instrument when testing aviators' oxygen has already been given briefly but is so simple that it will be repeated here for convenience in the more detailed discussion of points of interest. Referring to figure 1, gas from the nitrogen (or compressed air) cylinder is maintained in the saturator at a pressure of about 500 psi by means of the regulator. The cylinder of gas to be tested is connected to valve C. Valve B is opened widely and valve $\mathrm{A}$ is opened a little to permit a slight flow of gas from the saturator through the cell. The indicating circuit is adjusted, usually by changing resistance $R_{4}$ of figure 6 to produce any convenient scale reading of the galvanometer, and as soon as this reading is sufficiently constant, it is noted. This reading will be referred to as the balance-point. Valves A and B are closed in that order and valve $\mathrm{D}$ opened widely. Valve $\mathrm{C}$ is then opened to permit a moderately brisk flow of the gas to be tested through the cell. As soon as this gas reaches the cell, the galvanometer needle goes off scale on the dry side, corresponding to a high resistance of the detector. Valve D is now closed gradually, and the pressure is built up in the cell until the galvanometer needle swings back to the balance point. 
If the balance point is passed, it can be approached from the other side by carefully opening valve $D$. When a satisfactory check of the balance point has been reached, the pressure in the cell, $P_{x}$, is read. If there is any doubt that the pressure reading is sufficiently accurate, valve $\mathrm{C}$ or $\mathrm{D}$ is changed and another adjustment of the galvanometer to balance is made. When the observer is satisfied as to the balancing pressure, the thermometer is read and the concentration of water vapor is computed.

\section{b. Control of Standard Gas}

Details of the measurement will now be discussed. A saturator pressure, $P_{s}$, of 500 psi is selected for this particular purpose, because at ordinary room temperature, oxygen that meets Army-Navy specification for aviator's oxygen will bave a substantially equal balancing pressure, $P_{x}$. If there is the seme probable error in reading the two gages, the probable error of the comparison and the correction for deviation from the ideal gas laws are both minimized by making the two pressures equal.

One source of error is some uncertainty regarding the water content of the gas from a single saturator, and this is affected by the condition of the apparatus and the rates of flow employed. To begin with, the regulator rarely controls perfectly the pressure in the saturator. When flow is stopped, the pressure builds up a little; when flow is resumed the pressure falls, and this change tends to produce an increase in the water content of the gas as flow is increased. On the other hand, the evaporation of water within the cylinder tends to cool the gas and cause the water content to decrease during the test. If the rate of flow is too high, there may not be time for complete saturation. Observable effects of the two last mentioned causes are eliminated by using the double saturator previously described. Expansion at the valve causes a sharp drop in temperature of the gas with a tendency to precipitate the water as liquid. Fortunately most of the cooling takes place after the gas passes the narrowest passage in the valve, and any mist that is formed reevaporates, but sometimes water droplets formed on the surface of the metal are large enough when detached to cause a readable irregularity in the galvanometer reading. This effect can be completely eliminated by separating the outlet valve somewhat from the saturator and heating it a little with a small resistance coil. In a portable instrument, the valve is usually placed in a mass of metal large enough to prevent, by conduction, any important error from this source.

Usually in routine testing the outlet valve from the cell is left wide open for the standard gas, which is then assumed to be at atmospheric pressure in the detector cell. Of course it is not, or it would not flow. Consequently, the detector is exposed to a little higher concentration of water than would otherwise be the case. An auxiliary valve for limiting flow may be placed in series with valve $A$ and given a permanent setting, or the operator may make sure by trial that the flow is slight enough so that stopping it entirely makes no prompt and significant difference in the galvanometer reading. (A slow change in the galvanometer reading beginning after a little delay usually indicates diffusion into the cell from the outside.) The gas cooled by expansion may not reach room temperature by the time it arrives at the detector. This affects the reading in two ways; the lower temperature tends to condense more water in the film and thus cause a decrease of resistance, but a film containing a given quantity of water has a high temperature coefficient in the opposite direction. The first effect is likely to predominate, but for the duration and rate of flow usually employed a significant error does not occur because of differences of temperature of the detector when the "comparison" and "test" gases are interchanged. At high rates of flow, the temperature effect may become significant particularly when carbon dioxide or a refrigerant is being tested.

The discussion thus far would indicate that accuracy is promoted by making the flow of gas from the saturator very slow. We should add that at a very high rate of flow there is danger that liquid water will be carried over from the saturator mechanically, and that there is even the possibility that a sudden blast of gas over the detector will displace the film (this not infrequently happens with the gas to be tested if valves are manipulated carelessly).

Another factor of importance enters, however. The dry side of the instrument is rarely completely dry. Even though the parts of the apparatus are made, dried, and assembled with care, they seem to have the property of sorbing water from moist gas and giving it up later to a drier atmosphere in sufficient quantity to be readily detected. Gages are the worst parts of the apparatus in this respect; valve packings probably next, although the trouble from packings was largely eliminated by the use of Teflon. This exchange of moisture with surfaces and pockets within the apparatus generally affects the resistance of the detector when there is no flow of gas. A very small flow is affected to some extent, a large flow is not affected appreciably. For this reason we do not want gas from the saturator to flow too slowly; there is also a saving of time in reaching: equilibrium if the rate is increased. A rate of 250 $\mathrm{ml} / \mathrm{min}$ from the saturator is probably usually about right. It is not necessary to measure it, however; the observer soon learns to control it satisfactorily by other means. In a quiet room the gas escaping from the saturator at 500 psig should be barely audible to a normal ear, or silent but on the verge of audibility. The stream issuing from the small outlet of valve $B$ should not be perceptible to the hand unless the outlet is blocked momentarily with a thumb. The little spurt of gas when the pressure is relieved should be noticeable. Momentarily blocking the flow should also cause the galvanometer to respond decisively and at once. If the apparatus is thoroughly dry, the galvanometer reading should be the same for any rate of flow of gas sufficient to prevent diffusion upstream from the outlet valve and not great enough to build up appreciable pressure in the cell. To save time, it is better to adjust near the second limit than the first. 


\section{c. Troubleshooting}

The condition of the apparatus can usually be judged by the quick and simple tests that follow. With valve B partially closed, set the rate of flow (with valve A) at what is considered a little more than is desirable, to produce a slight pressure in the cell, then close the valve half way. A prompt but slight deflection toward the dry side (higher resistance) is the normal reaction if the system is dry, because the pressure in the cell diminishes. An immediate and permanent deflection toward the wet side indicates that water is entering the gas stream steadily as it evaporates from a packing, screw thread, or other source near the main channel of gas flow. A strong momentary deflection followed by the return to a steady reading, which is equal to or on the dry side of the reading obtained before the change of flow, indicates a nearly isolated pocket in which wet gas can accumulate and from which it is released only by a change of pressure. This pocket is usually the gage. If no deflection occurs when the rate of flow is changed it may be because the rate was initially too low to produce appreciable pressure in the cell, because the detector or indicator is insensitive, or because there is so much water in the cell or its connections that the gas is nearly saturated regardless of rate of flow.

The conditions may be further explored by checking and releasing the flow with a thumb at the outlet of valve B. Usually the galvanometer deflects sharply to the wet side when flow is stopped, and returns to the original reading when it is released. Sometimes a sequence of deflections will follow the release in such a way as to disclose a source of water, but this is less likely than with the less violent changes of flow produced by valve $A$.

If stopping and starting the flow at the outlet does not produce normal deflections of the galvanometer, the detector should be taken out of the cell and its response to the ever-changing humidity of room air noted, particularly the effect of bringing the detecting film near the operator's hand. If the indicator responds normally to this by promptly indicating a much lowered resistance, and particularly if the resistance of the detector in the cell was low, the apparatus is probably flooded. If exposing the detector to the atmosphere near the skin does not cause a sharp decrease of resistance, the system is inherently insensitive. If touching the electrodes with the finger does not produce a quick off-scale deflection, the trouble is in the electrical indicator and may be caused by a run-down battery, a broken connection, shunting by a low resistance, or the like. If the response to touching the electrodes is normal the trouble is in the film, which must be renewed.

The troubleshooting procedure is not as cumbersome as its description suggests. It should not require more than 2 or 3 min including the renewal of the sensitive film, if that is needed. Correcting faults in the electrical system and drying out the apparatus, when this is necessary, take longer.

If liquid water in quantity has gotten into the dry side of the apparatus, it is all but impossible to remove it completely except by disassembling the apparatus and baking the individual parts. If the moisture has come only from exposure to gases of fairly high humidity, it can usually be removed sufficiently by attaching a cylinder of dry gas and alternately building up and discharging a pressure of several atmospheres in the system. The cycle can be repeated every 2 or 3 sec. If 500 or 1,000 cycles are not effective, more thorough means of drying should be resorted to. This treatment is usually needed and usually successful after the apparatus has been out of use for a considerable period of time.

In addition to conditions previously mentioned, readings may be affected by changing battery voltage and the effect of changes of temperature and humidity on the measuring circuit, including the resistance of the insulation of leads and detector. Changes of capacitance resulting from movements of parts of the apparatus may also produce effects. When comparisons are completed promptly all these effects are practically equal on the readings for standard gas and sample and cancel out. Because they may change, it is advisable to complete comparisons promptly and with as little disturbance of the equipment as possible.

When tests are being made only to determine whether gas does or does not meet a specification, one takes account of the temperature and the setting of the regulator and computes the pressure at which gas that just meets the specification would balance. Thereafter until test conditions are changed, it is necessary only to run the pressure of the gas to be tested up to the predetermined value and note whether the galvanometer reading is to the right or left of that made with the standard gas. A setting with the standard gas is made with each cylinder, but this is easily done by an observer while someone else changes the test cylinder. It has been found practicable for one observer, with a sufficient crew of laborers to shift cylinders, to make tests by this method at the rate of 800 cylinders per 8-hr day. If it is to be determined how much water is present, not merely whether it is above or below a certain limit, more time is required. A test does not often require more than $2 \mathrm{~min}$ exclusive of the time required to move and connect the cylinder.

\section{d. Use of Compressed Gas and Standard}

Actually it is not practicable to measure the water content of most of the aviators' oxygen now made by direct comparison with gas from a saturator, even if the saturation pressure is 1,000 psi instead of the recommended $500 \mathrm{psi}$. If, for example, gas saturated at 1,000 psi and $25^{\circ} \mathrm{C}\left(77^{\circ} \mathrm{F}\right)$ and expanded to $1 \mathrm{~atm}$ matches gas at the usual charging pressure for storage cylinders, $2,000 \mathrm{psi}$, the water content of the stored gas is $4 \mu \mathrm{g}$ liter (after expansion to $1 \mathrm{~atm}$ ).

If the saturation pressure is $500 \mathrm{psi}$, the minimum measurable water content of the stored gas is $7 \mu \mathrm{g} /$ per liter. Most of the aviator's oxygen tested at the Bureau, after the oxygen manufacturers began trying to comply with the specified maximum of $20 \mu \mathrm{g}$ has contained less than $4 \mu \mathrm{g} /$ liter. To determine the water content actually present in such dry compressed gas, or to measure conveniently the water 
content below 0.2 or $0.3 \mathrm{mg} /$ liter of gas not initially under pressure, it is best to use a cylinder of fairly dry compressed gas as a secondary standard. Even for gases within range of direct comparison with the saturator, the cylinder is a convenience because less care is required than in the control of the saturator, and the composition of the standard gas is less dependent on temperature.

The gas to be used as the secondary standard must be compared frequently with gas from the saturator, for the water content of gas discharged from a cylinder invariably increases as the pressure falls, because the gas in the cylinder is always in near equilibrium with water adsorbed on the walls. This equilibrium is somewhat affected by temperature, but changes in the gas are slow.

A cylinder of gas to be used as a secondary standard in testing other cylinders can usually be selected from the lot. Otherwise it can be conveniently prepared in a laboratory in which compressed air and a vacuum pump are available by thoroughly drying an evacuated cylinder, admitting as much air from the room as is desired, and filling with compressed air, dried with a good desiccant after compression. As an example, assume that a water content of about $25 \mu \mathrm{g}$ /liter is desired in the secondary standard, that compressed air is available at $1,800 \mathrm{psi}$, and that the laboratory air is 50 percent saturated at $25^{\circ} \mathrm{C}$. The room air contains about $11,500 \mu \mathrm{g}$ of water per liter. At $1,800 \mathrm{psi}$, the cylinder will contain about 125 volumes (at $1 \mathrm{~atm}$ ) of air. Hence, we want about $(25 \times 125) / 11,500=$ $0.27 \mathrm{~atm}=210 \mathrm{~mm} \mathrm{Hg}$ of room air in the cylinder. As a secondary standard this gas can be used, while still at the initial pressure, to measure gas at 1 atm containing from about 25 to about $3,000 \mu \mathrm{g} /$ liter, or gas compressed at 1,800 psi at about 0.2 $\mu \mathrm{g}$ /liter after expansion. It will measure the quantity corresponding to saturation with liquid water in the cylinder of any gas above about $4 \mathrm{~atm}$. As the gas in the standard cylinder is used up, the usable range becomes narrower. The upper limit decreases because only lower comparison pressures (Pc of eq (2)) are available; the lower limit increases because some water evaporates from the cylinder walls.

The actual use of standard gas from cylinders differs from the use of a saturator in only one important respect. It is more often advantageous to use the secondary standard at other than a pressure of $1 \mathrm{~atm}$; unless advantage is taken of the fact that the barometric pressure is known more accurately than any small pressure can be measured on the gage attached to the instrument, accuracy is favored by making the pressures of standard and unknown gas as high as practicable. There is less reason than with the saturator to avoid excessive flows, and the observer may wish to gain speed by increasing somewhat the flow used. On the other hand, he may wish to conserve the supply because of the trouble of renewing it.

e. Operations Other Than Testing Compressed Gases

In most of the numerous possible applications of the method other than testing compressed gases, the gas to be tested is at atmospheric pressure. Instead of varying the pressure of the unknown gas to obtain a balance corresponding to an observation already made of the standard gas, the first galvanometer setting is made with the unknown gas, and the pressure of the standard, whether from saturator or calibrated cylinder, is varied to obtain a balance. The details of the procedure are so like those already given that they probably require no further description. Because we lack the ability to change the pressure of the unknown sample, the range of concentrations that can be measured with a single standard is narrower than in testing compressed gas, and we may need two secondary standards in addition to the saturator, whereas we rarely need more than one in work with compressed gases.

One source of error should be emphasized in connection with miscellaneous uses of the instrument. No rubber whatever can be used in any connection through which a gas to be tested flows. Exposing the gas to contact with any rubber surface is almost equivalent to exposing it to contact with an equal free surface of water.

While not to be compared with rubber as a trouble maker, oil dissolves enough water from the vapor phase to cause sluggish readings. The metal tubing used in the apparatus should be cleaned by blowing a stream of hydrogen or city gas through it while a burner is passed from inlet to outlet slowly enough to heat the section above the burner to redness. This leaves the inner surface of the metal free of both oil and oxide.

\subsection{Deviation from the Ideal Gas Laws and Computation of Results}

\section{a. Air, Oxygen, and Nitrogen}

The equations given in the introduction would serve to compute correctly the results of experiments provided all the gases involved, including water vapor, behaved as ideal gases. This statement is meant to include as a part of the behavior of ideal gases the commonly assumed rule that the mass of water vapor per unit volume in equilibrium with liquid water is independent of the presence of other gases. The rule is not strictly true, and the deviation from it is to be attributed to forces between the molecules of water vapor and other gases, which are the same forces that cause the deviations from Boyle's and Dalton's laws. Hence, it is correct as well as convenient to include the rule of constant vapor pressure among those defining relations for ideal gases. Actual gases have what has been described as a solvent effect on water vapor that tends to retain the water molecules in the gas phase.

The deviations from ideality can probably be described most clearly in terms of "fugacity," the tendency of a substance to "escape" from one phase into another. If this tendency is the same in two phases there can be no net transfer between them, that is, they must be in equilibrium so far as their water is concerned. When a steady reading is obtained with a detector exposed to one sample of 
gas, it is known that the fugacity of the water vapor in the gas phase and that of dissolved water in the detecting film are equal. If the same reading is obtained when the film is exposed to another sample of gas, the fact indicates that the water has the same fugacity in the two gases.

Actually, then, it is fugacities that are compared by the instrument. In an "ideal" system containing definite relative masses of water and gas, fugacity would be proportional to pressure, and equations 1 to 4 , which were introduced as only approximations in the first part of this paper, would be exact. In the actual system a relation between fugacity and pressure must be established by experiment.

This relation may be written by using the formula in which $F=A P\left(1+K P+K^{\prime} P^{2}+\ldots\right)$ in which $F$ is fugacity, $A$ is a constant involving the units in which $F$ is expressed, and which need not be stated because $A$ eventually cancels out, and constants $K, K^{\prime}, \ldots$. are to be determined by observation. The determination has been made for air in the following different ways: (1) by absorbing and weighing the water from measured volumes of air that had been saturated with water at different pressures, (2) by comparing the gravimetric determination of water with the electrical observations of the same sample and adjusting the constants in the equation to bring the two measurements into agreement, and (3) by comparing electrical measurements made with "comparison" gas saturated at different pressures and again adjusting the constants to give the same readings. The first of these three procedures in- volves no measurement with the electrical instrument, and the third involves nothing else. By substituting air and nitrogen for oxygen in the saturator and making the usual electrical measurements on the same gas, it was found that the difference in the constants for these three gases were outside the limit of accuracy of the measurements. This has been repeated several times with different samples of these gases and with the same result. Experiments in which the second and third methods were used were reported in [1]. They were limited to the pressure range 0 to $2,000 \mathrm{psi}$, and indicated that over this range $K^{\prime}$ and coefficients of powers of $P$ higher than 3 could be neglected. For $K^{\prime}=0$ and the pressure range covered, method 2 applied to the average of a set of gravimetric determinations led to a value $K=-1.5 \times 10^{-4}$; the third method led to $K=-1.7 \times 10^{-4}$. The opinion was there expressed that $1.7 \times 10^{-4}$ would be found to be the more accurate value. Later determinations by the first method, by Howerton [9] and by Diniak and Hughes [10] verified the value $K=-1.7 \times 10^{-4}$ as the best value to be used for pressures below 2,000 psi when $K^{\prime}$ is neglected.

A more extensive study by Diniak and Hughes [10] at pressures up to $6,000 \mathrm{psi}$ and room temperature $\left(25^{\circ} \mathrm{C}\right)$ led to the simultaneous values $K=-1.9 \times 10^{-4}$ and $K^{\prime}=1.4 \times 10^{-8}$. These values, when used to predict the water content of gases saturated with water vapor and at pressures from 0 to $3,000 \mathrm{psi}$, yield results that are in excellent agreement with the observations of Webster [11] and others. Putting these values in eq (2), we obtain

$$
W_{x}=S \frac{P_{c} P_{w}\left(1-1.9 \times 10^{-4} P_{c}+1.4 \times 10^{-8} P_{c}^{2}\right)}{P_{s} P_{x}\left(1-1.9 \times 10^{-4} P_{s}+1.4 \times 10^{-8} P_{s}^{2}\right)\left(1-1.9 \times 10^{-4} P_{x}+1.4 \times 10^{-8} P_{x}^{2}\right)} .
$$

The values of $K$ and $K^{\prime}$ change with changing temperature and have not been determined with high accuracy except at "room temperature." Their variation between $20^{\circ}$ and $30^{\circ} \mathrm{C}$ are probably outside the accuracy of measurement. Some data for higher and lower temperatures are to be presented and discussed in [10].

\section{b. Computer and Its Use for Compressed Gas}

The solution of eq (5) involves ascertaining the value of $S$, the saturation pressure of water at the temperature of test, and reducing four pressures from gage readings to the absolute scale before the operations of addition and multiplication indicated by the equation can be performed. The time involved in doing this by longhand is greatly in excess of that needed to make the tests themselves. A computer in the form of a circular slide rule for quickly and simply performing the necessary computations was described in [1]. This has been redesigned [12] to take account of the new values for deviations from ideality and to cover wider ranges of pressure $(0$ to $6,000 \mathrm{psi})$ and temperaure $\left(-100^{\circ}\right.$ to $\left.+120^{\circ} \mathrm{F}\right)$.
The new computer is shown in figure 14. It consists of a base disk and two rotating disks with protruding tabs, both of which contain windows of transparent plastic through which scales on lower disks can be read. On the base disk an outer loga rithmic (ordinary slide rule) scale divides the circumference of the circle into three decades. It is marked "Water vapor-milligram per liter at $70^{\circ} \mathrm{F}$." Near the center is a scale marked "Temp. 'F." It is formed by laying off logarithmically the vapor pressures of water from $-30^{\circ}$ to $+120^{\circ} \mathrm{F}$, and marking each pressure with the temperature at which it occurs.

The middle disk has only one major scale, marked " $\left(P_{c}\right)$ comparison pressure." On it, absolute pressures are laid off logarithmically, but each point is marked with the corresponding gage pressure (difference between absolute and barometric pressures) when the barometric pressure is 14.7 psi. At one end of the comparison-pressure scale is a short scale marked "alt. correction" that will be referred to as the "altitude scale" when corrections are discussed.

The upper disk has two principal scales, marked, "Test gage pressure $\left(P_{x}\right)$ ", and a scale marked " $\left(P_{s}\right)$ saturation pressure." There is also an auxiliary 
scale marked "Frost point below $-30^{\circ} \mathrm{F}$." It is used as an extension of the temperature scale (Scale T) on the base plate.

The computer can be used in a great many ways, most of which will be readily understood by comparison with the ordinary slide rule. Multiplications and divisions are made by adding and subtracting angles just as they are made by adding and subtracting lengths on a linear slide rule. Frequently-used conversion factors can be introduced by markings on the appropriate scales as the value of $\pi$ is commonly marked on the linear slide rule. The widths of the tabs have been shosen to permit direct readings of water concentration in units other than milligrams per liter. There is room to the left of the altitude scale for marking additional conversion factors in the range 1.2 to 100 . An example is shown in figure 15 , in which the middle disk has two markings,

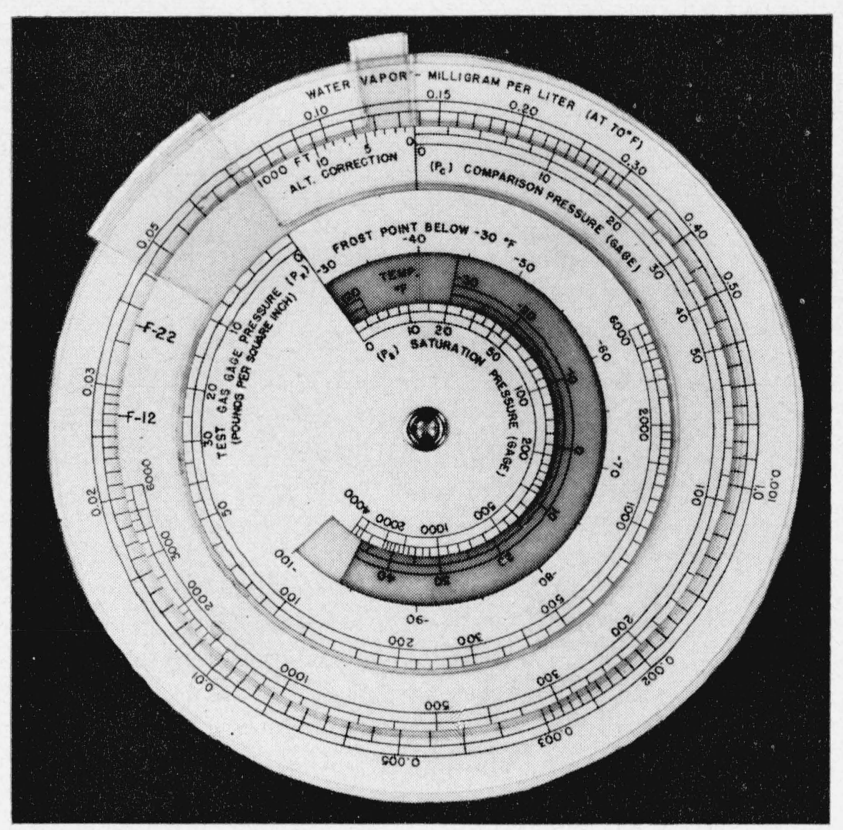

Figure 15. Computor.

$\mathrm{F}-12$ and $\mathrm{F}-22$, that read directly in parts of water per million parts by weight in the two commercial refrigerants Freon 12 and Freon 22, respectively.

The quantity of water in a gas is designated at various times and for several reasons by a variety of systems and units. It is often necessary or convenient to convert from one system to another. The computer is designed to facilitate, particularly, interconversions among the following:

1. Weight of water per unit volume of gas at a standard temperature: (a) Milligrams per liter at $70^{\circ} \mathrm{F}$ (almost identical with ounces per thousand cubic feet). (b) Pounds per 10,000 cubic feet.

2. Parts by weight of water per thousand parts of gas.

3. Vapor pressure of water.

4. Dewpoint (frost point below $32^{\circ} \mathrm{F}$ ).

5. Relative humidity.

6. Percentage by volume of vapor in gas.
In the use of the instrument, for testing the dryness of a compressed gas, by comparison with gas from a saturator at high pressure, the pressure in the saturator in pounds per square inch gage is set opposite its temperature; the index of the "comparison pressure scale" is set on the "test gas pressure" scale and the water content of the gas being tested (after expansion to $1 \mathrm{~atm}$ at $70^{\circ} \mathrm{F}$ without change of composition) is read opposite the comparison pressure.

After this setting has been made, the tabs of either disk can be used as the glass slide is used on a linear slide rule to mark a position for further computation.

The angular widths of the tabs have been chosen so that when the right-hand edge of the wider one reads milligrams per liter on the logarithmic scale, the left edge reads pounds of water per 10,000 cubic feet of gas; when the right edge of the narrow tab reads milligrams per liter, the left edge reads pounds of water per thousand pounds of air. The vapor pressure of water in millimeters of mercury is numerically equal to 1.017 times the number of milligrams per liter at $70^{\circ} \mathrm{F}$, a factor that can be read on the computer but can usually be neglected. Subject to this error, the outer scale reads directly in vapor pressure units. When the zero of the comparisonpressure scale indicates milligrams per liter at $70^{\circ} \mathrm{F}$, the 5,000 mark of the same scale (elongated to aid the memory) indicates percentage of water vapor by volume.

If the water content is less than $1 \mathrm{mg} / \mathrm{liter}$, the dewpoint is read directly on the temperature scale under milligrams per liter on the outer scale. If the water content is more than $1 \mathrm{mg} /$ liter (at about $0^{\circ} \mathrm{F}$ ), the numbers on the outer scale must be multiplied by 1,000 to correspond to the dewpoint (frost point below $32^{\circ} \mathrm{F}$ ) on the adjacent temperature scale. If the right edge of the wide tab, on the upper disk, is brought to the water content in milligrams per liter on the outer scale, the frost point is read on the scale marked "Frost point below - $30^{\circ} \mathrm{F}$ " at the lowest point $\left(-30^{\circ} \mathrm{F}\right)$ on the temperature scale. The decimal point must be watched carefully in this operation; it is not taken care of automatically.

The relative amount of water in gases under two conditions is ascertained by finding an angle between the points representing concentrations under each condition. This angle can be set readily as that between the edges of the two protruding tabs. Then, if the middle disk is rotated, the small disk is carried along without disturbing the angle until one tab is above 1.0 of the outer scale on the base disk. The other tab then reads directly the ratio of concentration of water in the two cases. If one of the two conditions represents saturation, the ratio found is "relative humidity" as the term is ordinarily used.

For the sake of simplicity, pressures used in both eq (4) and (5) are expressed as absolute pressures. However, the pressures marked on the computer are gage pressures when the barometric pressure is 1 normal atm, 14.7 psia. If the barometric pressure differs from 1 normal atm the result obtained with the computer is somewhat in error. The correct result may be obtained by converting gage readings 
to absolute pressures by adding the barometric pressure and introducing into eq (7), or more easily by changing each gage reading to what it would have been had the barometer read 14.7, and using the computer.

Variations of the barometer at a given point can usually be neglected for ordinary work, but the differences between points at sea level and altitudes of several thousand feet are too great to be disregarded. For convenience in the routine testing of compressed gases by the usual procedure, the total correction for the difference between normal pressure at a given altitude and normal pressure at sea level has been marked on the computer as an extension of the comparison pressure scale and labeled "Alt. correction." The correction was computed for the case in which a sample containing 20 $\mu \mathrm{g}$ of water per liter is compared with a gas saturated at $500 \mathrm{psig}$ and expanded to the average barometric pressure at that altitude. It is applied at the end of the usual computation by reading the scale opposite the altitude in question instead of opposite the zero of the comparison pressure scale. The corrected result represents the water content of the sample at $70^{\circ} \mathrm{F}$ and 1 normal atm and is not exact except for the conditions of test specified. It may or may not be useful under different conditions of test; this can usually be determined by solving a typical set of real or assumed data with the computer and comparing with the result of a direct substitution in eq (7). If the difference is considered negligible, the correction scale can be used routinely for testing under approximately the conditions assumed.

\section{Applications of the Method}

\subsection{Compressed Gases}

The application of the method to the measurement of water in such "permanent" gases as air and oxygen has probably been described in enough detail. It should be added that the composition of the gas in a cylinder usually changes during its discharge because water is adsorbed in the oxide (or rust) coating of the cylinder wall, and tends to evaporate to maintain equilibrium with the gas phase as vapor is discharged with the gas. A typical behavior of an ordinary steel cylinder of gas is shown in figure 16 . The cylinder was new, had been dried "thoroughly" by its manufacturer and filled with oxygen by direct evaporation from the liquid. A series of experiments with different cylinders dried by the same procedure and filled at the same time with gas containing about $10 \mu \mathrm{g}$ /liter showed that there was no significant change in composition after charging to full pressure in the case of an aluminum and a stainless steel cylinder and only negligible though measurable increases during discharge; an ordinary cylinder previously in service for "dry" gases showed about the same trend as figure 16. An oxygen cylinder long used in welding service, deeply rusted and visibly wet, was heated and purged until it was

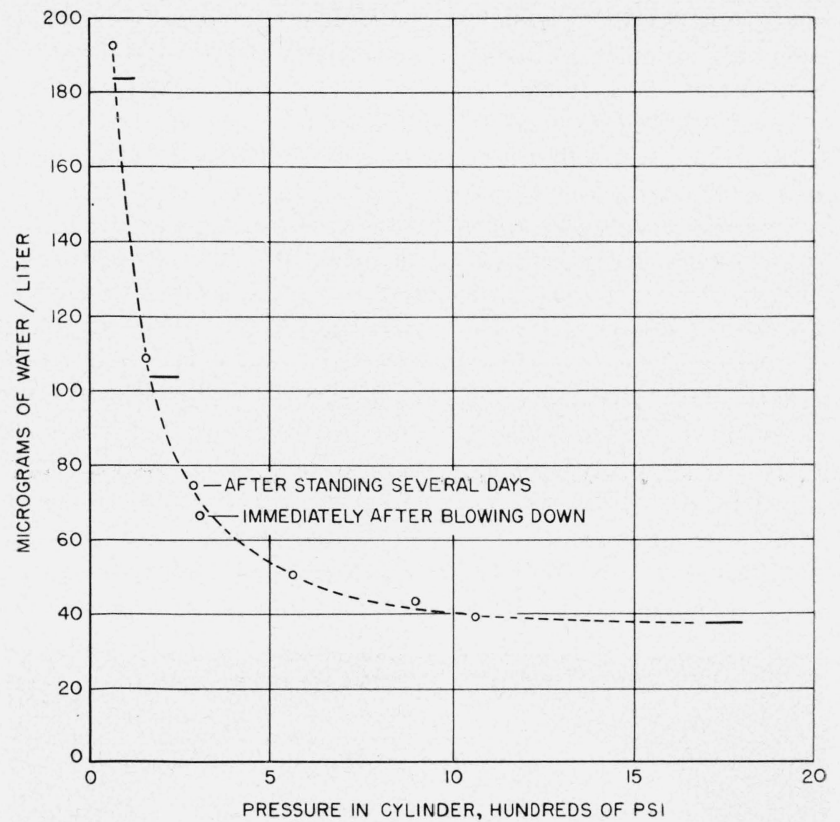

FIGURE 16. Water vapor in gas from a cylinder of compressed oxygen determined gravimetrically and electrically.

-, Gravimetric test; $\bigcirc$, electrical test,

apparently thoroughly dry; but after charging with a dry gas, it delivered gas with a high water content that increased almost accurately in inverse proportion to cylinder pressure.

Each gas shows individual deviations from ideality and for accurate work at high pressures this fact must be taken into account by substituting appropriate values for the constants in eq (5). Hydrogen and helium are very close to ideal gases and zero values for constants $K$ and $K^{\prime}$ can probably be used without significant error. Nitrogen, oxygen, and argon are practically indistinguishable, and eq (5) applies to all three without change. An early approximate determination indicated that at pressures at which the term containing $P^{2}$ can be ignored the value of $K$ for methane should be $2.4 \times 10^{-4}$ making the correction factor by which methane pressures are multiplied $(1-0.00024 \mathrm{P})$. This is to be compared with the best value for air, when the term in $P^{2}$ is omitted, of (1-0.00017P).

Two of the Freons were studied in some detail by comparing results of the electric and gravimetric methods. It was concluded that at $25^{\circ} \mathrm{C}$, the value of $K$ should be $-1.0 \times 10^{-6}$ for dichlorodifluoromethane (Freon 12) and $1.2 \times 10^{-5}$ for chlorodifluoromethane (Freon 22), while the value of $K^{\prime}$ for both remained the same as for air $\left(K^{\prime}=1.4 \times\right.$ $\left.10^{-8}\right)$.

\subsection{Liquefied Gases}

"Gases" such as carbon dioxide, propane, butane, sulfur dioxide, methyl chloride, and the Freons, are usually almost entirely in the liquid phase at the time of sampling and we are interested in the com- 
position of the liquid; but we must make our measments in the gas phase. There are two solutions to the difficulty. A "partition coefficient" of the water between gas and liquid phases can be determined by experiment or taken from the literature; but this coefficient changes with temperature and to some extent with pressure and is probably hardly worth ascertaining except for rapid approximate tests.

A better method is to permit a slight flow of the liquid through a capillary channel into a heater where it is vaporized completely and continuously. If, as in a refrigerating machine, there is a driving mechanism, it may be possible to return the gas tested to the system without loss. Apparatus and procedures are described by Diniak, Hughes, and Fujii [3] and by Brisken [14] for following changes in a closed system of this kind. The analyses represented by figure 29 in reference [1] were obtained with simpler equipment that discharged the vapor sampled to the air.

Usually the comparison gas used in testing any gas will be air or its equivalent for this purpose, hence in the use of eq (5) only the term $\left(1-K P_{x}+\right.$ $\left.K^{\prime} P_{x}^{2}\right)$ is affected by the nature of the gas analyzed. If, in this case, the computer is used in determining $W_{x}$, the result should be multiplied by the quotient of the correction factor for air at pressure $P_{x}$ divided by that for the gas tested at the same pressure. Thus, if the gas tested is methane, if its water content is represented by $W_{m}$, and if $W_{a}$ is the water content shown by the use of the computer,

$$
\frac{W_{a}}{W_{m}}=\frac{\left(1-.19 \times 10^{-4}+1.4 \times 10^{-8} P^{2}\right)}{\left(1-2.3 \times 10^{-4} P_{x}\right)} .
$$

From the data of Wiebe and Gaddy [13] at $25^{\circ} \mathrm{C}$, and in the lower part of the reported pressure range, the correction for the fugacity of water vapor in carbon dioxide was computed [1] to be (1-6.05X $10^{-4} P+1.2 \times 10^{-7} P^{2}$, which agreed very well with observations made on a cylinder of carbon dioxide. The data from which this factor was taken show a reversal of direction at the pressure of liquefaction of the carbon dioxide-rich phase, and the correction no longer applies. Hence the water content of carbon dioxide is to be determined at as low a value of $P_{x}$ as practicable. Making the division indicated by the ratio $W_{a} / W_{m}$, a determination of water in carbon dioxide made with air as the comparison gas and calculated on the computer should be multiplied by the factor $\left(1+4.15 \times 10^{-4} P+1.5 \times 10^{-7} P^{2}\right)$.

The maximum pressures in the gas phase of the more easily liquefied substances such as propane, butane, and the Freons, minimize the importance of a correction for pressure.

In sampling materials such as the refrigerants, even from the gas phase, any appreciable expansion of the gas in the sampling line before the detector is reached results in cooling that may affect the result unless the gas is brought to detector temperature through a heat exchanger. Long metal connections and slow rates of flow minimize trouble from this source.

\subsection{Liquids}

The method is convenient and very rapid for making comparisons of the water contents of many liquids. Its usefulness depends on the fact that if air is brought to equilibrium with the liquid, by bubbling or otherwise, the fugacity of water vapor will be equal in the two phases and can be matched with that of gas from a saturator or other known source.

A convenient method of bringing the detecting film to equilibrium, through the gas phase, with the liquid to be tested is to attach the detector to the upper end of a tube, that is dipped into the liquid to nearly its full length. Figure 17 shows a convenient form of apparatus. A glass tube $\mathrm{A}$ with a flared top snaps into a stainless steel fitting with hooklike fingers, an action similar to that of a snap garmentfastener on an enlarged scale. Ordinary test tubes of small size have been found satisfactory for the glass tubes. For small samples, a capillary tube with flared end could be used. They may receive a little spherical grinding to make a substantially tight fit with B. The detector D, shown here in cross section, is attached to B by nut $\mathrm{E}$. The glass tube has an opening at the bottom, F, and at one side, G. The springs $\mathrm{C}$ hold the tube firmly against the detector block. The connection between tube and detector block is tight enough to prevent appreciable leakage under a few millimeters of water pressure, and the tube can be plunged into the liquid without excessive care and without touching the detector tip although it is only a few millimeters from the liquid surface. Since the liquid flows into the tube from well below

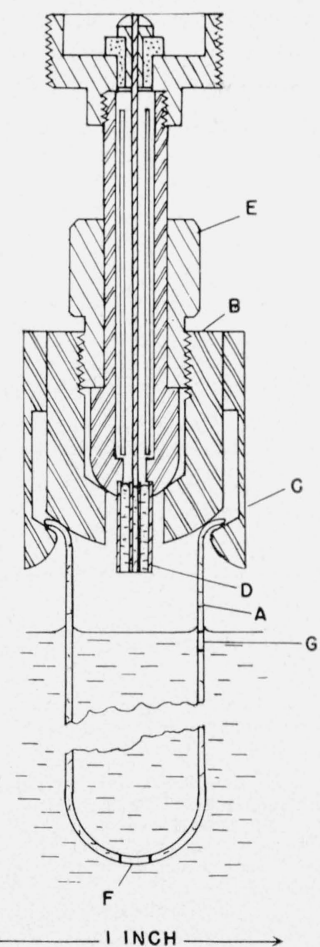

Figure 17. Arrangement used in testing water vapor in equilibrium with a liquid. 
the surface, a reading is obtained that is not much affected by the composition of the liquid immediately at the surface, which sometimes differs materially from that of the bulk of the sample.

The method is extremely sensitive for water in liquids, like the hydrocarbons, that dissolve very little water, less so for ethers, ketones, etc., and least sensitive for such things as the alcohols and nitric and sulfuric acids. Unfortunately, the quantitative significance of the fugacity in terms of water content is different for each liquid; but once worked out on an empirical basis, it should permit a determination almost as quick and in many cases (such as that of the hydrocarbons) much more accurate than is possible with a hydrometer. It is also more specific for water and less subject to the effect of impurities, particularly the homologs of the principal constituent of the liquid, than is density or refractive index.

It should be possible to use the fact that the fugacities of the same quantity of water are very different in different substances to determine the composition of their binary mixtures by adding a known amount of water to their mixtures. This subject is discussed briefly in [2].

\subsection{Solids}

Interchanges between solids and gases are readily followed in detail. A simple example is the determination of the drying capacity of solid desiccants by passing a measured stream of air of predetermined humidity through them and measuring the water in the outflowing air at intervals. Figure 18 shows the results of tests of three desiccants by this method. The tests were made with saturated air at room temperature, which was fairly constant at an average of $73.8^{\circ} \mathrm{F}$. Desiccant and saturator

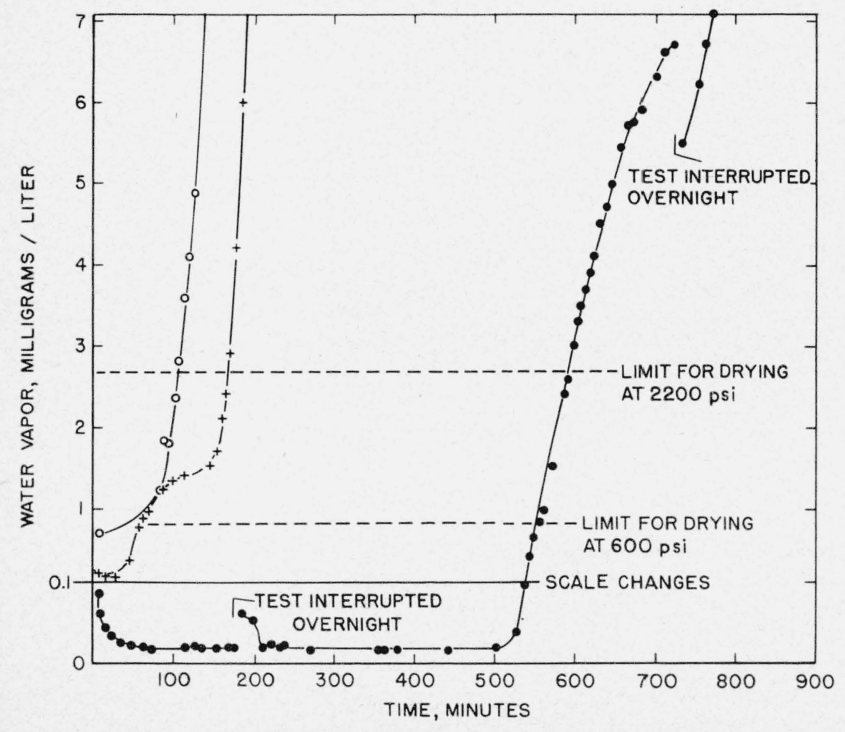

FIGURE 18. Drying capacity of three desiccants. ○, Desiccant No. 1 ; +, desiccant No. 2; silica gel dried at $275^{\circ} \mathrm{C}$. were initially at the same temperature, but there was some (unmeasured) increase in the temperature of the desiccant, contained in a length of half-inch iron pipe, and probably a small reduction in temperature of the second of two saturators, steel cylinders filled with wet sand used in series. The water content of the saturated air was about $30 \mathrm{mg}$ per liter (about $1.8 \mathrm{lb}$ of water per $100 \mathrm{lb}$ of dry air) and the "space velocity" through the desiccant was about 12.5 (12.5 volumes of air passed per minute through unit volume of the desiccant). Thus the "breakpoint" for silica gel at $500 \mathrm{~min}$ represents the drying of $6,250 \mathrm{cu} \mathrm{ft}$ of air per cubic foot of desiccant-filled dryer volume.

The silica gel in this case was a freshly "reactivated" (dried) lot of old material of the grade supplied to the government for "mothballing", military equipment. It may be of interest that the other two desiccants were of two different types delivered in hermetically sealed containers by different contractors for use in drying aviators oxygen at high pressure. The composition of these desiccants is not stated here because their inferior performance is believed to represent faulty preparation rather than inherent unsuitability of the classes of materials to which they belong.

The "limits" shown on the figure indicate the dryness required in compressed gases at 600 and $2,200 \mathrm{psi}$ if the specification of $0.02 \mathrm{mg}$ /liter in the expanded gas is to be met. The rather impressive possibilities of high-pressure drying are shown by the fact that the silica gel would have dried 606,000 times its volume of air saturated with water at 2,200 psi and $70^{\circ} \mathrm{F}$ before any of it would have contained more than $0.02 \mathrm{mg} /$ liter after expansion to atmospheric pressure. The contamination of the desiccant near the outlet of its tube by contact with moist air during activation and preliminary handling is shown by the high initial portion of the drying curve. Had this contamination been avoided, oxygen equal to approximately one-half million times the volume of the desiccant would have been dried to contain only ten parts of water per million by weight.

The removable water content of a desiccant, a soil, or similar material can be determined readily with more or less accuracy by any of several procedures. The simplest is to integrate the water content found in a sample of air passed over the solid under whatever conditions are desired. An apparatus successfully used in determining the dryness of silica gel is illustrated and the procedure is described in [1]. If the water is not evolved at a convenient rate for satisfactory measurement in the flowing stream, the water may be frozen out with solid carbon dioxide or liquid air and determined as a whole after vaporizing and diluting by whatever procedure is desired.

\subsection{Application to Solids of the Test for Water in Liquids}

Water held by capillarity or adsorption on powdered solids such as paper or sand can be determined very rapidly by shaking a sample with a 
suitable liquid and determining the water in the resulting solution by the use of the dipping tube previously described for liquids. The liquid used as a solvent for water must be calibrated in advance by adding known small amounts of water to some of it. It should be chosen so that it is never saturated by the water in the sample (alcohol, acetone, sulfuric acid, and other "completely miscible" liquids never are) and is still reasonably sensitive. For small samples of very dry materials, ether or a hydrocarbon can be used. The method is believed applicable to many materials that are hard to dry such as candies, fats and greases, soaps, and emulsions of various types; but in applications of each kind the effects of the material other than water on the fugacity of water in the solvent would have to be considered.

\subsection{Determination of Substances That Can Be Converted to Water}

The method is often applicable to the determination of substances such as oxygen or oxygen compounds easily reducible by hydrogen, or to hydrogen or known organic compounds, the hydrogen of which can be burned to water. Circumstances particularly favorable to its use exist in the case of argon, which is required for some purposes in extreme purity. Gas at cylinder pressure is first tested for water vapor in the normal manner. Then the gas, still at as high pressure as facilities will permit, is mixed with hydrogen, passed through a small combustion furnace containing platinized asbestos or equivalent catalyst, and again tested for water. Oxygen is computed from the difference between water in the original sample and that found after combustion with hydrogen; or both gases may be dried before entering the furnace by freezing out with liquid air, in which case the water found after combustion represents oxygen in the sample without correction. A sample may then be taken through the furnace after mixing with oxygen instead of hydrogen; the water produced is then a measure of hydrogen or hydrogen compounds in the gas and is to be interpreted in terms of the reducing gas most likely to be present, usually a residue from the process of removing oxygen. If natural gas was used to burn out oxygen, the water should probably be calculated as methane. If these analyses are conducted at or near the usual charging pressures of commercial cylinders, $100 \mathrm{~atm}$ or more, the method is sensitive enough to determine parts of water per ten million; the volume of sample and of reagent gases required are negligible; and the method is rapid when once the needed equipment has been assembled.

\subsection{Permeability of Membranes}

The permeability of membranes to water can be readily measured. The membrane is clamped between the halves of a "cell" with shallow chambers on each side. One side may be completely filled with water, putting the liquid in contact with the membrane; but usually the permeability to water vapor in a saturated atmosphere is desired and the cell is set with the membrane horizontal and the surface of the water in the lower chamber near to but not in contact with it.

The transfer of water through the membrane may be measured in either of two ways. For membranes of high permeability such as rubber, the best method is to measure the water vapor in the inlet and outlet of a constantly flowing stream. Membranes of low permeability are best tested by observing the build-up of moisture in a closed cell. A suitable apparatus is shown in [1].

The principal difficulty in the use of the second method is that of knowing or controlling the initial condition of the membrane. When permeability determinations are made in a flowing stream the test can be continued until a steady state is reached and the initial condition becomes unimportant. For comparative purposes, however, the static method is quicker and may be accurate enough in spite of the initial uncertainty. It may be conveniently conducted as follows:

With water in the lower chamber, the chamber above the membrane is swept out with a rapid stream of dry air for a preselected time to produce an approximately steady water gradient, in the membrane, from saturation at one surface to substantial dryness at the other. Flow is then stopped and the time required to build up the moisture content of the "dry" chamber to a predetermined reading is noted. With a "dry" chamber 1 in. deep at a temperature of $25^{\circ} \mathrm{C}$, it requires about $40 \mathrm{sec}$ to reach a relative humidity of 25 percent in the case of a cellulose acetate film $0.03 \mathrm{~mm}$ thick. With a Saran film $0.05 \mathrm{~mm}$ thick about $1 \mathrm{hr}$ was required to reach a relative humidity of 10 percent. Other tests are reported in [1].

Either of the methods described is easily modified to determine permeability to hydrogen or oxygen. In the static method both a water vapor detector and a heated wire are located in one chamber. The apparatus is thoroughly dried before the test, then one chamber is swept out with dry hydrogen and the other with dry oxygen or air. Unless permeability is very great, the hot wire burns the permeating gas with practical completeness, replacing it with water. If the detector and catalytic burner are on the hydrogen side the build-up of water shows the permeability of the membrane to oxygen; if on the oxygen side, permeability to hydrogen is measured. Instead of hydrogen, permeability to an organic gas or vapor can be determined by substituting it for hydrogen.

Substantially, the procedure here recommended for permeability has several times been used for detecting leaks in apparatus with satisfactory results. 


\section{References}

[1] E. R. Weaver and R. Riley, Measurement of water in gases by electrical conduction in a film of hygroscopic material and the use of pressure changes in calibration, J. Research NBS 40, 169 (1948) RP1865; Anal. Chem. 23, 216 (1948).

[2] E. R. Weaver, Electrical measurement of water vapor with a hygroscopic film, Anal. Chem. 23, 1076 (1951).

[3] A. W. Diniak, E. E. Hughes, and Minoru Fufii, Determination of water content in Freon-12 circulating in a refrigerating system, Refrig. Eng. 62, No. 2, 56 (Feb. 1954).

[4] E. R. Weaver and P. G. Ledig, Detection of water vapor in closed pipes, Tech. Pap. BS 17, 637 (1923) T242; Ind. Eng. Chem. 15, 931 (1923).

[5] F. W. Dunmore, An electrical hygrometer and its application to Radio Meteorology, J. Research NBS 20, 723 (1938) RP1102.

[6] F. W. Dunmore, An improved electric hygrometer, J. Research NBS 23, 701 (1939) RP1265.
[7] Arnold Wexler, Electric hygrometers, NBS Circ. 586 (1957).

[8] A. Wexler, S. B. Garfinkel, F. E. Jones, S. Hasegawa and $\mathrm{A}$. Krinsky, A fast responding electric hygrometer, J. Research NBS 55, 71 (1955) RP2606.

[9] E. K. Howerton (private communication).

[10] E. E. Hughes and A. W. Diniak (in preparation).

[11] T. J. Webster, J. Soc. Chem. Ind. (London) 69, 343 (1950).

[12] A. W. Diniak and E. R. Weaver, A new computer for calculating the water content of gases, J. Research NBS 56, 269 (1956) RP2674.

[13] R. Wiebe and V. L. Gaddy, vapor phase composition of carbon dioxide-water mixtures, J. Am. Chem. Soc. 63, 475 (1941).

[14] W. R. Brisken, moisture migration in Hermetic refrigerating Systems, Refrig. Eng. 63, 42 (July 7, 1955).

Washington, October 25, 1957. 